\title{
Correlation of Surface Toll-Like Receptor 9 Expression with IL-17 Production in Neutrophils during Septic Peritonitis in Mice Induced by $E$. coli
}

\author{
Yunjia Ren, ${ }^{1,2}$ Li Hua, ${ }^{3}$ Xiuping Meng, ${ }^{2,3}$ Yue Xiao, ${ }^{1}$ Xu Hao, ${ }^{3}$ Sheng Guo, ${ }^{1}$ Peiyan Zhao, \\ Luowei Wang, ${ }^{1}$ Boqi Dong, ${ }^{3}$ Yongli Yu, ${ }^{3}$ and Liying Wang ${ }^{1}$ \\ ${ }^{1}$ Department of Molecular Biology in College of Basic Medical Sciences and Institute of Pediatrics in First Hospital, \\ Jilin University, Changchun 130021, China \\ ${ }^{2}$ Department of Endodontics, School and Hospital of Stomatology, Jilin University, Changchun 130021, China \\ ${ }^{3}$ Department of Immunology in College of Basic Medical Sciences, Jilin University, Changchun 130021, China
}

Correspondence should be addressed to Yongli Yu; ylyu@mail.jlu.edu.cn and Liying Wang; wlying@mail.jlu.edu.cn

Received 16 October 2015; Revised 31 December 2015; Accepted 3 January 2016

Academic Editor: Kong Chen

Copyright @ 2016 Yunjia Ren et al. This is an open access article distributed under the Creative Commons Attribution License, which permits unrestricted use, distribution, and reproduction in any medium, provided the original work is properly cited.

\begin{abstract}
IL-17 is a proinflammatory cytokine produced by various immune cells. Polymorphonuclear neutrophils (PMNs) are the first line of defense in bacterial infection and express surface Toll-like receptor 9 (sTLR9). To study the relationship of sTLR9 and IL-17 in PMNs during bacterial infection, we infected mice with $E$. coli intraperitoneally to establish a septic peritonitis model for studying the PMNs response in peritoneal cavity. We found that PMNs and some of "giant cells" were massively accumulated in the peritoneal cavity of mice with fatal septic peritonitis induced by E. coli. Kinetically, the CD11b ${ }^{+}$PMNs were increased from $20-40 \%$ at 18 hours to $>80 \%$ at 72 hours after infection. After E. coli infection, sTLR9 expression on $\mathrm{CD}_{11 \mathrm{~b}^{+}}$and $\mathrm{CD} 1 \mathrm{~b}^{-} \mathrm{PMNs}$ and macrophages in the PLCs were increased at early stage and deceased at late stage; IL-17 expression was also increased in CD11b ${ }^{+}$PMNs, CD11b PMNs, macrophages, and $\mathrm{CD}^{+} \mathrm{T}$ cells. Using experiments of in vitro blockage, qRT-PCR and cell sorting, we confirmed that

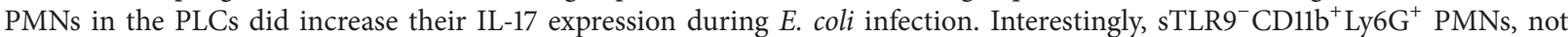
sTLR9 ${ }^{+} \mathrm{CD}_{11 b^{+}} \mathrm{Ly}_{6 \mathrm{G}^{+}}$PMNs, were found to be able to increase their IL-17 expression. Together, the data may help understand novel roles of PMNs in septic peritonitis.
\end{abstract}

\section{Introduction}

Sepsis affects approximately 700,000 people annually and accounts for about 210,000 deaths per year in the US. Its incidence is rising at rates between $1.5 \%$ and $8 \%$ per year, despite continuous progress in the development of antimicrobial therapeutics and supportive cares [1]. Most of the sepsis is caused by bacteria and bacteria of abdominal origin contribute to the second major reason for sepsis. This type of sepsis is designated as abdominal sepsis or septic peritonitis. The septic peritonitis is the host's systemic inflammatory response to the bacteria, initiated by the pathogen associated molecule patterns (PAMPs) including lipopolysaccharide and lipid A from Gram-negative bacteria and lipoteichoic acid and peptidoglycan from Gram-positive bacteria [2]. The inflammatory initiation leads to the release of chemokines, such as interleukin-8 (IL-8), and proinflammatory cytokines, such as tumor necrosis factor- $\alpha$ (TNF- $\alpha$ ), IL-1, IL-6, and IL12 , in a massive amount. The cytokines, if not appropriately controlled, may severely impair the functions of vital organs or systems, resulting in death [2]. Data from the CIAOW study (complicated intra-abdominal infections worldwide observational study) showed that the overall mortality rate was $10.5 \%$ in the patients with septic peritonitis in a worldwide context [3].

Septic peritonitis is characterized by a massive infiltration of neutrophils into the peritoneum in response to bacterial invasion, where they are activated and act as a first line of 
defense against the bacteria [4]. Morphologically, the mature neutrophils are unique among the other white blood cells by their lobulated nucleus, which inspired the renaming of them as polymorphonuclear neutrophils (PMNs) [5]. Based on cytokine production, macrophage activation, expression of Toll-like receptor (TLR), and surface antigen expression, murine PMNs have been classified into three types [6]: normal PMN (PMN-N), PMN-I, and PMN-II. PMN-I produces IL-12/CCL3, activates macrophages in a classical way, expresses TLR2/TLR4/TLR5/TLR8, and has a CD49d ${ }^{+} \mathrm{CD}_{11 \mathrm{~b}^{-}}$ phenotype. PMN-II produces IL-10/CCL2, activates macrophages in an alternative manner, expresses TLR2/TLR4/ TLR7/TLR9, and possesses a CD49d ${ }^{-} \mathrm{CD}_{11 b^{+}}$phenotype. PMN-N rarely produces cytokine/chemokine, displays no effect on macrophage activation, and expresses TLR2/TLR4/ TLR9, with CD49d $\mathrm{d}^{-} \mathrm{CD}_{11}{ }^{-}$phenotypes. The PMN-N may convert to PMN-I or PMN-II in response to bacterial infections [6]. Recently, macrophages have been reported to cooperate with neutrophils by promoting extravasation and activation of PMNs, even their clearance of bacteria [7].

Accumulated evidence revealed that Toll-like receptors (TLRs) could play a fundamental role in induction of hyperinflammation and tissue damage in sepsis. TLRs are pattern recognition receptors (PRRs) that sense microbial invasion and initiate innate immune responses. Positioned at the cell surface, TLR4 is essential for sensing lipopolysaccharide of Gram-negative bacteria and TLR2 is involved in the recognition of a large panel of microbial ligands, while TLR5 recognizes flagellin. Endosomal TLR3, TLR7, TLR8, and TLR9 are specialized in the sensing of nucleic acids produced notably during viral infections or during bacterial infections [8]. Conventionally, TLR9 is thought to sense microbial DNA in endolysosomes and not at the cell surface. Recently, it has been found that TLR9 is expressed on the surface of human and mouse PMNs, that the surface TLR9 (sTLR9) senses DNA in PMNs, and that sTLR9 expressing PMNs (sTLR9 ${ }^{+}$PMNs) have roles in inducing rapid inflammation [9]. Human and mouse PMNs spontaneously express sTLR9, and the sTLR9 expression is upregulated in response to PMN stimulation [10]. In front of TLR9 ligands, sTLR9 ${ }^{+}$PMNs could be activated, leading to cytokine secretion and CD11b upregulation [10]. Notably, TLR9 stimulation was demonstrated to be detrimental in mice with bacterial sepsis. TLR9 $^{-1-}$ mice exhibited lower serum inflammatory cytokine levels, higher bacterial clearance, and greater survival after experimental peritonitis induced by cecal ligation and puncture (CLP). A single injection of TLR9 antagonist protected the wide type mice, even when administered as late as 12 hours after CLP [11]. It has been proposed that, during infection, sTLR9 ${ }^{+}$PMNs could be involved in the detrimental effect by releasing massive proinflammatory cytokines, including IL- 6 and TNF- $\alpha$, and possibly other cytokines in response to PAMPs $[12,13]$.

Interleukin-17 (IL-17) is a cytokine family that signatures T helper 17 (Th17) cell subset and contains six members (IL17A to IL-17F), among which IL-17A is considered as one of the major proinflammatory cytokines mediating the innate and adaptive immune responses against bacterial infections
[14]. In addition to Th17 cells, $\gamma \delta \mathrm{T}$ cells, innate lymphoid cells (ILCs), mast cells, PMNs, and macrophages are also IL17 producing cells [14]. Notably, innate immune cell-derived IL-17 constitutes a major element in the immune response against infectious agents by recruiting PMNs to the sites of infections and by inducing the production of antimicrobial peptides, CXC chemokines, and granulocyte colony stimulating factor (G-CSF) $[15,16]$. In bacterial infection, PMNs act to produce increased IL-17, which in turn recruits more PMNs to join the fighting against invaded bacteria, resulting in increased production of innate immune cell-derived IL-17 $[16,17]$. IL-17 was found to work in an IL-23-IL-17 axis which was critical for the survival of the host infected with bacteria [18]. In the axis, tissue-infiltrating PMNs could be the main source of IL-23 [19] which induces production of IL-17 from macrophages [20].

In the present study, we kinetically observed the infiltration of PMNs and expression of sTLR9 and IL-17 on/in the PMNs in the peritoneal lavage cells (PLCs) of mice intraperitoneally infected with various doses of Escherichia coli (E. coli), aiming to find the correlation of the expression of sTLR9 and IL-17 on/in the PMNs during the development of bacterial septic peritonitis. The achieved results could provide a basis for further investigation on the roles of sTLR9 expressing PMNs and IL-17 producing PMNs in bacterium caused septic peritonitis.

\section{Materials and Methods}

2.1. Antibodies and Reagents. The monoclonal antibodies of APC-conjugated rat anti-mouse CD45 antibody (561689), $\mathrm{PE}-$ conjugated rat anti-mouse CD14 antibody (561711), PEconjugated rat anti-mouse CD11b antibody (561689), APC$\mathrm{Cy}^{\mathrm{m}} 7$-cojugated rat anti-mouse CD3 antibody (560590), and APC-conjugated rat anti-mouse Ly-6G antibody (560599) were purchased from BD bioscience. The FITC-conjugated active anti-TLR9 monoclonal antibody (26C593.2) was from Abcam; FITC-conjugated anti-mouse IL-17A antibody (506908) and PerCP-Cy ${ }^{\text {min }}$ 5.5-conjugated rat anti-mouse IL17A (3354955) antibody were from Biolegend. Trizol reagent (NC0301) was from Invitrogen. cDNA Synthesis Kit (Transgene biotech, I21021) and two-step SYBR green qPCR assays (Transgene biotech, G31227) were from Biotech.

2.2. E. coli Strain and Mice. E. coli strain of JM109 was recovered from lyophilized powder by being suspended into LB medium and then cultured on LB agar plate at $37^{\circ} \mathrm{C}$ overnight. The single colonies of $E$. coli on the plate were used as a group of original seed E. coli.

Female ICR mice were purchased from the Experimental Animal Center, Medical College of Norman Bethune, Jilin University, and maintained in microisolator cages under specific pathogen-free conditions. All the mice were used at 6 to 8 weeks of age. The experimental manipulation of mice was undertaken in accordance with the National Institute of Health Guide for the Care and Use of Laboratory Animals, with the approval of the Scientific Investigation Board of Science \& Technology of Jilin Province. 
2.3. Preparation of E. coli Culture. To prepare E. coli culture, each single colony of $E$. coli was picked up and cultured in $5 \mathrm{~mL} \mathrm{LB}$ medium at $37^{\circ} \mathrm{C}$ with shaking at $200 \mathrm{rpm}$. When the OD value $\left(A_{600}\right)$ of the culture reached $1.4, E$. coli was harvested from the culture by centrifugation and mixed with $20 \%$ glycerol solution. The resultant glycerol E. coli was stored at $-20^{\circ} \mathrm{C}$ as working E. coli seeds. The working seed E. coli were seeded into $\mathrm{LB}$ medium and cultured at $37^{\circ} \mathrm{C}$ till the OD value reached 0.7 followed by harvesting the $E$. coli pellet after centrifugation at $4000 \mathrm{~g}$ for $5 \mathrm{~min}$. The E. coli pellet was diluted in a serial tenfold, plated on an eosin methylene blue agar plate, and then cultured at $37^{\circ} \mathrm{C}$ for 14 hours. The colonyforming units (CFUs) of the E. coli culture were calculated and determined as approximately $0.8 \times 10^{8} \mathrm{CFUs} / \mathrm{mL}$. For animal experiment use, the $E$. coli pellet was washed twice using sterile $0.9 \% \mathrm{NaCl}$ (saline) and then resuspended in $1.0 \mathrm{~mL}$ saline containing $0.4,0.8,1.6$, and $2.4 \times 10^{8} \mathrm{CFUs}$ of E. coli, respectively, and was ready to use for infecting mice.

2.4. Induction of Bacterial Septic Peritonitis and Preparation of PLCs. For inducing bacterial septic peritonitis, mice were injected intraperitoneally (i.p.) with $1.0 \mathrm{~mL}$ of E. coli preparations containing $0.4,0.8,1.6$, and $2.4 \times 10^{8} \mathrm{CFUs} / \mathrm{mL}$ in sterile saline, respectively. The saline injection was used as control. The survival of the mice was monitored every 4 hours for 4 days.

To harvest the peritoneal lavage cells (PLCs) from mice either infected with $E$. coli or injected with saline, the mice ( $n \geq 3$ per group) were euthanized at defined time points with $50 \mathrm{mg} / \mathrm{kg}$ pentobarbital sodium followed by washing peritoneal cavities using $6 \mathrm{~mL}$ per mouse of ice-cold phosphatebuffered saline (PBS). The peritoneal lavage fluid was centrifuged at $750 \mathrm{~g}$ for 5 minutes at $4^{\circ} \mathrm{C}$ for harvesting the PLCs. The PLCs were resuspended in cold PBS for further use.

2.5. Cell Culture and Treatment. PLCs were harvested from the naïve mice and maintained in RPMI 1640 supplemented with $10 \%(\mathrm{~V} / \mathrm{V})$ fetal bovine serum (FBS) (GIBCO) and antibiotics (100 IU of penicillin/mL and $100 \mathrm{IU}$ of streptomycin/mL). In experiments using viable bacteria, antibiotics were not added to the culture medium during the isolation, washing, or subsequent culturing period. No bacterial contamination was observed in PLCs cultured in the absence of antibiotics. Cells were counted and then plated in 24-well cell culture plates (Costar, Cambridge, MA) at an approximate density of $1 \times 10^{6}$ cells/well. The PLCs were cocultured with E. coli at $1 \times 10^{5}$ or $1 \times 10^{6} \mathrm{CFUs} /$ well or saline as a vehicle control for 14 hours, and then they were cultured with BFA for another 4 hours, in a $5 \% \mathrm{CO}_{2}$ humidified incubator at $37^{\circ} \mathrm{C}$. The PLCs were collected and stained with FITC-labeled antiIL-17 mAb, followed by flow cytometry analysis to detect the expression of IL-17.

2.6. Cell Counting. To count the numbers of cells in each peritoneal lavage sample, the samples were spin down for harvesting the cell pellets. The cell pellets were smeared on slides and then stained using hematoxylin-eosin (HE) followed by counting the cell numbers on hemocytometer (Beckman Coulter, Fullerton, CA) and taking photos of the cells.

2.7. Flow Cytometry. For surface staining, the PLCs were stained with fluorescence-conjugated mAbs against CD45, CD11b, and sTLR9, respectively, for 30 minutes at room temperature in the dark followed by washing twice with PBS. For IL-17 intracellular staining, the PLCs were surface stained as described above and then fixed with $4 \%$ paraformaldehyde and permeabilized with $0.1 \%$ saponin followed by staining with FITC-conjugated anti-IL17A monoclonal antibody. All stained cells were analyzed by flow cytometer FACSCalibur (BD) and CytoFLEX (Beckman Coulter). Live cells were carefully gated by forward and side scattering. Data were analyzed with FlowJo software (FlowJo 7.6.1).

2.8. Cell Sorting. The PLCs were harvested from mice $(n \geq$ 6 per group) either infected with $E$. coli or injected with saline. The PLCs were stained with fluorescence-conjugated mAbs against CD14, CD11b, and CD3 for 30 minutes at room temperature in the dark, followed by washing twice with PBS. The stained cells were sorted using BD FACS Aria II by the methods described in Figure 5(g). The neutrophils were sorted by selection for $\mathrm{CD}^{-} \mathrm{CD} 14^{-} \mathrm{CD} 11 \mathrm{~b}^{+}$cells, and $\mathrm{T}$ cells were sorted by selection for $\mathrm{CD}^{+}$cells, according to the manufacturer's recommendations. T cells (defined as $\mathrm{CD}^{+}$ cells with a purity $>83 \%$ of living cells) and PMNs (defined as $\mathrm{CD}^{-} \mathrm{CD} 14^{-} \mathrm{CD}^{-11 b^{+}}$cells with a purity $>96.7 \%$ of living cells) were obtained.

2.9. $q R T-P C R$. Total RNA was isolated from the PLCs with Trizol reagent and reverse-transcribed using cDNA Synthesis Kit. Quantitative real-time PCR (qRT-PCR) was performed using two-step SYBR green qPCR assays and the target mRNAs were identified by the specific primers as follows: IL-17A, forward: 5'-AAGGCAGCAGCGATCATCCCT; reverse: $3^{\prime}$-TCTTCATTGCGGTGGAGAGTCC; GAPDH, forward: $5^{\prime}$-ATCACCATCTTCCAGGAGCGA; reverse: $3^{\prime}$ TCTCGTGGTTCACACCCATCA. The data were acquired using the Step One ${ }^{\text {Ti }}$ real-time PCR system (Applied Biosystems). The procedure of the target mRNA amplification was as follows: 1 cycle at $95^{\circ} \mathrm{C}$ (30 seconds) followed by 40 cycles at $95^{\circ} \mathrm{C}$ (5 seconds) and $64^{\circ} \mathrm{C}$ (31 seconds). Each assay plate included negative controls with no template. The relative amount of gene expression was calculated according to the formula $2^{-\Delta \Delta \mathrm{Ct}}$, in which $\Delta \mathrm{Ct}=[\mathrm{Ct}($ gene $)-\mathrm{Ct}(\mathrm{GAPDH})]$ and $\mathrm{Ct}$ is the crossing threshold value returned by the PCR instrument for every gene amplification.

2.10. Statistical Analysis. Comparisons between groups were conducted using analysis of Student's $t$-tests. Survival curves of mice were estimated using the Kaplan-Meier method and compared using the log-rank test. We considered the resulting $P$ values of less than 0.05 (95\% CI) to be statistically significant. Statistics were analyzed using GraphPad Prism 5.0 for Windows (San Diego, CA). 


\section{Results}

3.1. The Establishment of E. coli Induced Septic Peritonitis in Mice. To understand how neutrophils contribute to the development of sepsis, we first established a murine model of septic peritonitis induced by Escherichia coli (E. coli). The female ICR mice, 10 in each group, were intraperitoneally injected with $2.4 \times 10^{8}, 1.6 \times 10^{8}, 0.8 \times 10^{8}$, and $0.4 \times 10^{8}$ colony forming units (CFUs) of $E$. coli, respectively, and then monitored for their physical conditions and survival. Around 6 hours after the infection, all of the 10 mice received $2.4 \times$ $10^{8} \mathrm{CFUs}$ of $E$. coli, 8 out of the 10 mice received $1.6 \times 10^{8} \mathrm{CFUs}$ of $E$. coli, and 5 out of the 10 mice that received $0.8 \times 10^{8}$ CFUs of $E$. coli began to exhibit multiple neurological symptoms, including dispirited behavior, staggered gait, and trembling, but these phenomena were not present in all of the 10 mice that received $0.4 \times 10^{8} \mathrm{CFUs}$ of $E$. coli or saline. Around 18 hours after the infection, the infected mice began to die. Around 48 hours, the infected mice underwent a massive death, especially in those that received high infectious dose of E. coli. By 72 hours after the infection, $80 \%, 60 \%$, and $40 \%$ of the mice infected with $2.4,1.6$, and $0.8 \times 10^{8}$ CFUs of $E$. coli, respectively, died and yet $100 \%$ of the mice which were infected with $0.4 \times 10^{8} \mathrm{CFUs}$ of $E$. coli or received saline survived (Figure 1). The results indicated that the infection with $E$. coli at $1.6 \times 10^{8} \mathrm{CFUs}$ and $2.4 \times 10^{8} \mathrm{CFU}$ could induce septic peritonitis in ICR mice.

3.2. The Infiltration and Morphology of Neutrophils in PLCs of Mice with Septic Peritonitis Induced by E. coli. Since the polymorphonuclear cells (PMNs) are documented as the first innate immune cells recruited at inflammation sites and play a central role in host defense [21], we next collected the peritoneal lavage cells (PLCs) of the mice at 18, 48, and 72 hours after infection, respectively, for observing the infiltration and morphology of the PMNs in the PLCs. The collected PLCs were fixed on glass slides, stained with $\mathrm{H} \& \mathrm{E}$ dye, and photographed. A massive infiltration of PMNs was observed in the PLCs from the infected mice. At 18 hours after infection, in the PLCs of the mice infected with 1.6 and 2.4 $\times 10^{8}$ CFUs of $E$. coli, the majority of the cells with the size of 0.2 0.4 micrometer were PMNs with a typical lobulated nucleus. Interestingly, there occurred a portion of giant cells, with the size of nearly 1.0 1.6 micrometer, characterized by lobulated nucleus that was squeezed to the marginal zone of the inner cell membrane. However, at 48 or 72 hours, the giant cells disappeared in the PLCs of the mice infected with 1.6 and $2.4 \times 10^{8}$ CFUs of E. coli (Figure 2(a)). Morphologically, there are four types of cells in the PLCs, including PMNs, macrophages, lymphocytes, and the giant cells (Figure 2(b)). When counting the cells, we found that at 18,48 , and 72 hours, PMNs constituted 50\%-80\% and macrophages constituted $20 \%-40 \%$ of the PLCs from the mice infected with 4 doses of E. coli, respectively, compared with nearly $30 \%$ for PMNs and $60 \%$ for macrophages in the PLCs from the mice that received saline. At 18 hours, interestingly, there were about $20 \%$ of the giant cells in the PLCs of the mice infected with 1.6 and $2.4 \times 10^{8}$ CFUs of E. coli (Figure 2(b), upper right).

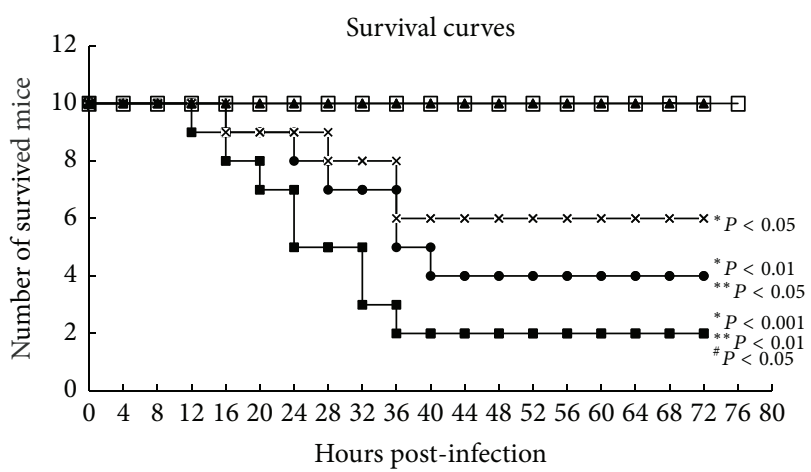

$$
\begin{aligned}
& \rightarrow-2.4 \times 10^{8} \text { CFUs } \quad \square 0.4 \times 10^{8} \text { CFUs } \\
& \rightarrow-1.6 \times 10^{8} \text { CFUs } \quad \longrightarrow \text { Saline } \\
& \rightarrow-0.8 \times 10^{8} \text { CFUs }
\end{aligned}
$$

FIGURE 1: Survival curves of mice with septic peritonitis induced by $E$. coli. ICR mice were infected intraperitoneally with $E$. coli at different doses for inducing septic peritonitis. Saline-injected mice were as controls. The survival of the mice was counted. ${ }^{*}$ Compared to control mice; ${ }^{* *}$ compared to mice infected with $0.4 \times 10^{8}$ CFUs of E. coli; ${ }^{\#}$ compared to mice infected with $1.6 \times 10^{8} \mathrm{CFUs}$ of $E$. coli.

Noticeably, when the mice died of the infection, we collected the PLCs immediately and observed and found that plenty of bacteria coexisted with the PMNs in the PLCs of the mouse infected with $1.6 \times 10^{8}$ CFUs of E. coli for 31 hours (Figure 2(c)). These results indicate that neutrophils can move to infected peritoneal cavity by infiltration and change their morphologies after engulfing bacteria possibly.

3.3. The Correlation of Neutrophil Numbers in PLCs with Severity of Septic Peritonitis in Mice Infected with E. coli. During septic peritonitis, a large number of PMNs were recruited to the peritoneal cavity of the infected mice. To find the correlation of the numbers of PMNs at various time points with the severity of the disease in mice infected with $E$. coli, the PLCs of the mice were collected at 18, 48, and 72 hours after infection, counted by hemocytometer or flow cytometry after staining with fluorescence-labeled mAb of anti-CD45 and anti-CD11b. At 18 hours, the numbers of PLCs were nearly $1 \times 10^{6}$ cells $/ \mathrm{mL}$ of peritoneal lavage fluid (PLF) in the mice received saline (control mice), significantly increased in the mice infected with 3 doses of $E$. coli in a dose dependent manner, and even reached nearly $3 \times 10^{6}$ cells $/ \mathrm{mL}$ of PLF in the mice infected with $2.4 \times 10^{8} \mathrm{CFUs}$ of $E$. coli $(P<0.05)$. At 48 hours, the numbers of PLCs were less than $1 \times 10^{6}$ cells $/ \mathrm{mL}$ of PLF in control mice and significantly increased to over $3 \times$ $10^{6}$ cells $/ \mathrm{mL}$ of PLF in the mice infected with three doses of E. coli and even to about $4 \times 10^{6}$ cells $/ \mathrm{mL}$ of PLF in the mice infected with 1.6 and $2.4 \times 10^{8}$ CFUs of E. coli $(P<0.05)$. At 72 hours, the numbers of PLCs were decreased to $0.5 \times$ $10^{6}$ cells $/ \mathrm{mL}$ of PLF in control mice and decreased to nearly $0.5 \times 10^{6}$ cells $/ \mathrm{mL}$ of PLF in the mice infected with three doses of E. coli (Figure 3(a)). In the PLCs from the infected mice, most of the cells were $\mathrm{CD} 45^{+}$nucleated leukocytes, representing PMNs, macrophages, and lymphocytes, respectively. At 18 


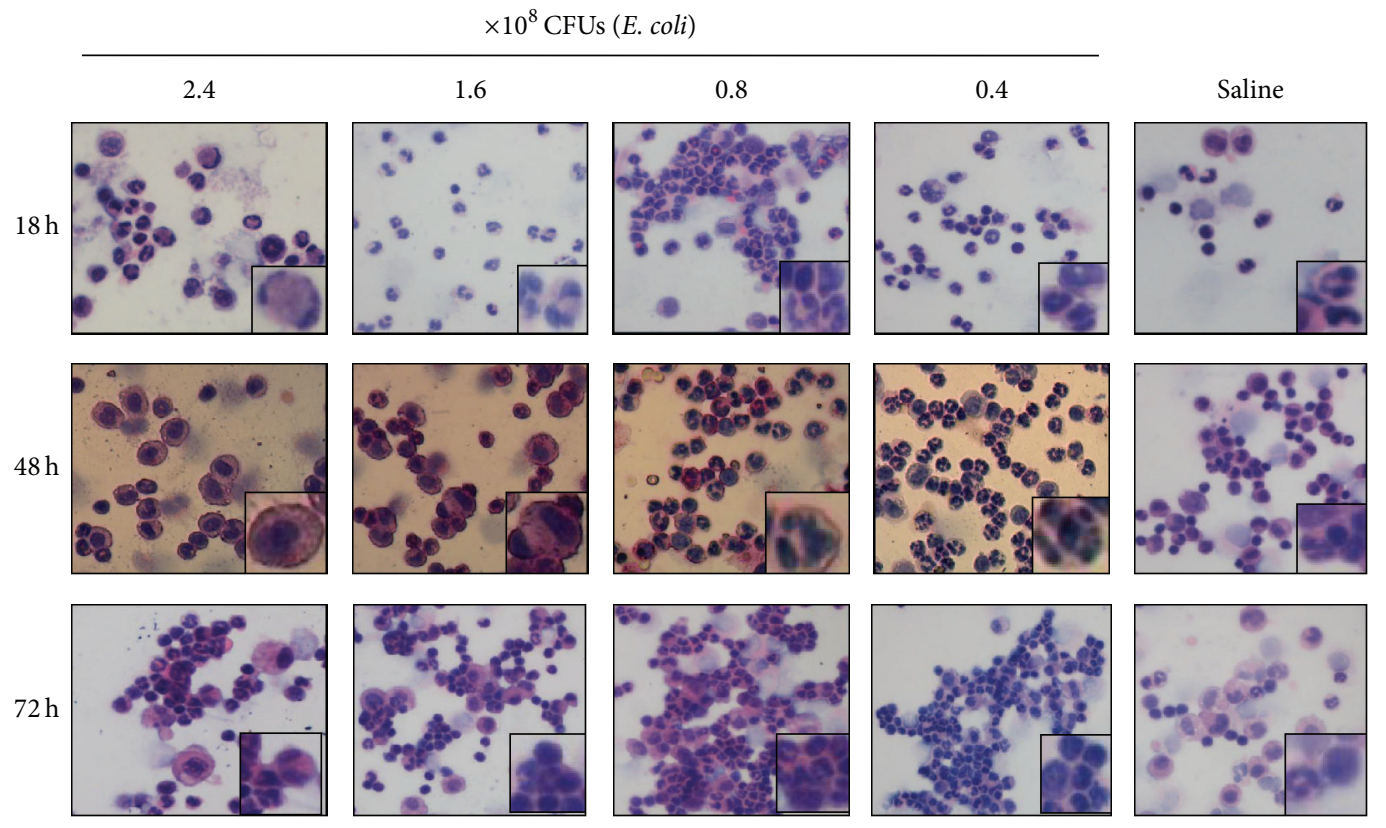

(a)
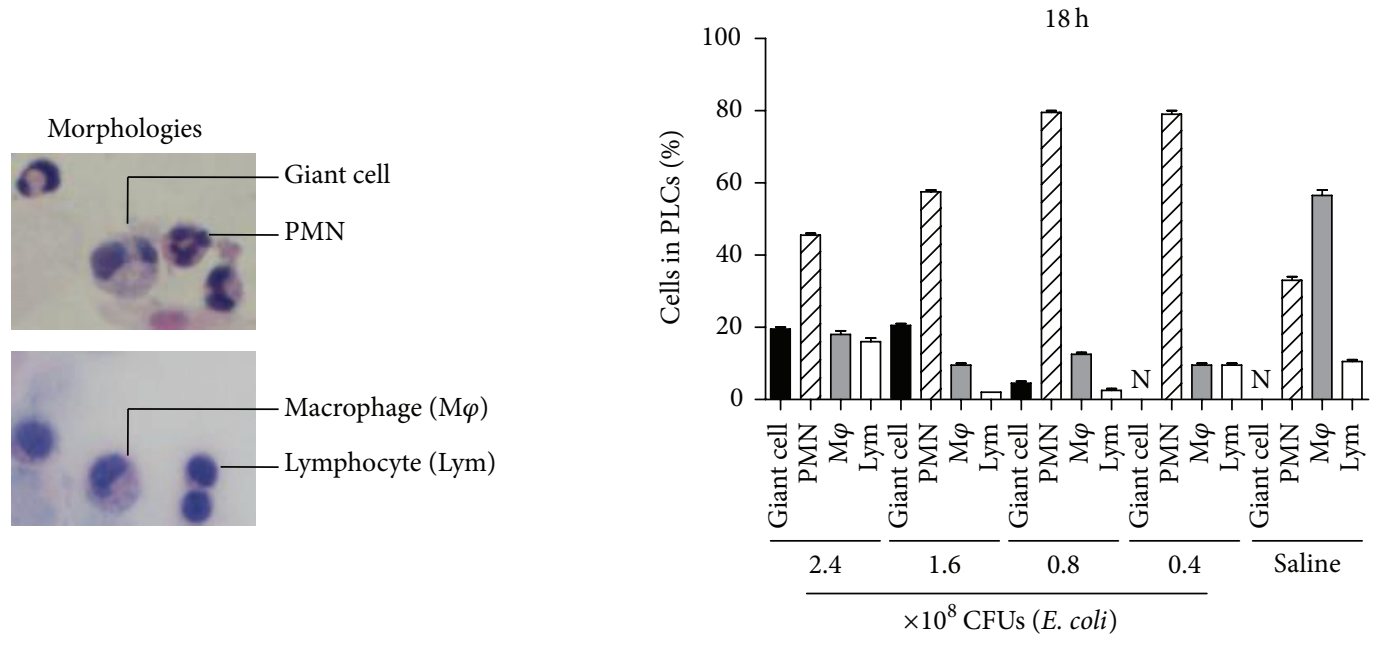

$48 \mathrm{~h}$
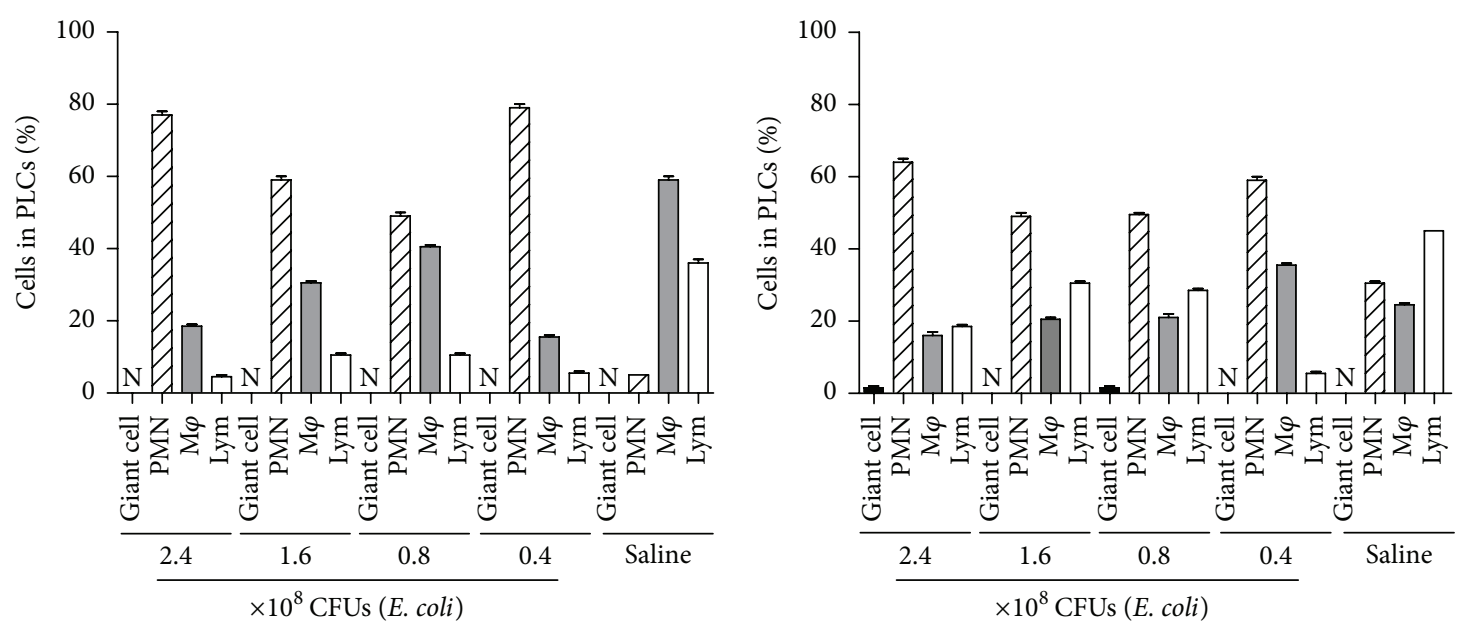

(b)

Figure 2: Continued. 

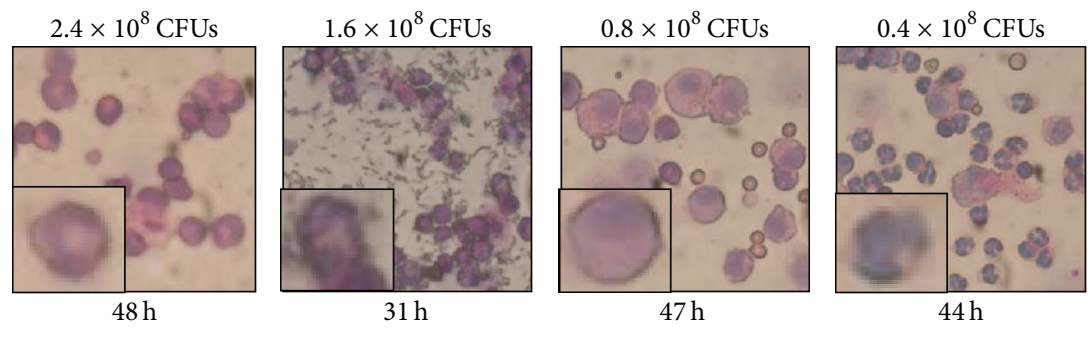

Death time

(c)

FIGURE 2: Morphologies of peritoneal lavage cells (PLCs) from mice infected intraperitoneally with E. coli. ICR mice were infected intraperitoneally with 3 doses of E. coli or received saline and then sacrificed at 18, 48, and 72 hours, respectively, for harvesting their PLCs. The PLCs were stained with H\&E dye followed by taking photos and counting cell numbers under a microscope. (a) Photos of PLCs from killed mice. (b) The cell counts based on the PLC morphologies. (c) Photos of PLCs from dying mice. Each group is composed of 6 mice.

hours, the PMNs, macrophages, and lymphocytes were displayed on the left, middle, and right of the histogram, respectively, sequentially based on their nuclear structure and fluorescence intensity. At 48 and 72 hours, the PMNs were found to be shifted to the right upper quadrant, indicating that the PMNs were with more ovulated nuclei and expressed elevated CD45. As shown in Figure 3(b), at 18 hours after infection, the $\mathrm{CD} 45^{+}$PMNs constituted $61.5 \%, 49.6 \%$, and $56.4 \%$ of the PLCs in the mice infected with $0.8,1.6$, and $2.4 \times 10^{8}$ CFUs of $E$. coli, respectively, compared with $32.5 \%$ in the control mice. At 48 hours, the $\mathrm{CD} 45^{+}$PMNs were increased to 59.5\%, $63.7 \%$, and $54.7 \%$ in the PLCs from the mice infected with $0.8,1.6$, and $2.4 \times 10^{8} \mathrm{CFUs}$ of E. coli, respectively, compared with $41.2 \%$ from the control mice. At 72 hours, the CD $45^{+}$ PMNs constituted $62.2 \%, 62.8 \%$, and $63.5 \%$ of the PLCs in the mice infected with $0.8,1.6$, and $2.4 \times 10^{8} \mathrm{CFUs}$ of $E$. coli, respectively, compared with $39.5 \%$ from the control mice.

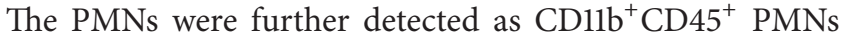

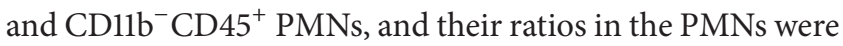
calculated. As shown in Figure 3(c), the $\mathrm{CD}_{11 b^{+}} \mathrm{CD} 45^{+} \mathrm{PMNs}$ constituted $49 \%, 36 \%$, and $13 \%$ of the PMNs in the PLCs from the mice infected with $0.8,1.6$, and $2.4 \times 10^{8}$ CFUs of $E$. coli for 18 hours, respectively. At 48 hours after the infection,

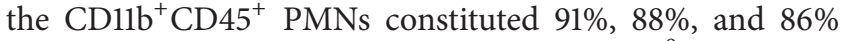
in the mice infected with $0.8,1.6$, and $2.4 \times 10^{8}$ CFUs of $E$. coli, respectively. At 72 hours after the infection, the CD1lb PMNs reached around $96 \%$ in all infected mice. Oppositely, at 18 hours, the $\mathrm{CD}^{-} \mathrm{b}^{-} \mathrm{PMNs}$ constituted $51 \%, 64 \%$, and $87 \%$ of the PMNs in the PLCs from the mice infected with $0.8,1.6$, and $2.4 \times 10^{8}$ CFUs of E. coli, respectively. At 48 hours after the infection, the CD11b ${ }^{-}$PMNs constituted $9 \%$, $12 \%$, and $14 \%$ in the mice infected with $0.8,1.6$, and 2.4 $\times 10^{8} \mathrm{CFUs}$ of $E$. coli, respectively. At 72 hours after the infection, the CD11b ${ }^{-}$PMNs only accounted for around $4 \%$ in all infected mice (Figure 3(c)). The results indicated that the peritoneal infection of $E$. coli induced massive infiltration of $\mathrm{CD} 45^{+}$PMNs. Among the CD $45^{+}$PMNs, CD11b ${ }^{+}$PMNs were increased with the progression of infection. In parallel, the $\mathrm{CD}^{-11 b^{-}}$PMNs were decreased. At 18 and 48 hours after infection, the ratios of $\mathrm{CD}_{11 b^{+}} \mathrm{PMNs}$ or $\mathrm{CD}^{-11 b^{-}} \mathrm{PMNs}$ were correlated with the doses of $E$. coli negatively or positively.
3.4. The Expression of Surface TLR9 (sTLR9) on Neutrophils and Macrophages in PLCs with Development of Septic Peritonitis in Mice Infected with E. coli. Since primary human and mouse blood neutrophils were reported to be able to express a functional sTLR9 [10], we tried to detect whether the expression of sTLR9 was different on $\mathrm{CD}_{11 \mathrm{~b}^{+}} \mathrm{PMNs}$ and $\mathrm{CD} 1 \mathrm{~b}^{-}$ PMNs and correlates with development of septic peritonitis in mice. The PLCs collected from the mice which were infected with $E$. coli or received saline were gated for detecting the expression of sTLR9 on both $\mathrm{CD}_{11 b^{+}}$and CD11b ${ }^{-}$PMNs (Figure 4(a)). Results showed that, at 18 hours after infection, the ratios of sTLR9 ${ }^{+} \mathrm{CD}_{11 b^{+}}$PMNs were increased to $57 \%$, $51 \%$, and $70 \%$ of the CD11b ${ }^{+}$PMNs in the mice infected with $0.8,1.6$, and $2.4 \times 10^{8}$ CFUs of E. coli, respectively $(P<0.05)$, compared to $12 \%$ in the mice that received saline control (control mice). At 48 hours, the ratios of sTLR9 ${ }^{+} \mathrm{CD}_{11 b}{ }^{+}$ PMNs were decreased to $2.3 \%, 2.3 \%,(P<0.05)$ and $8 \%$ in the infected mice, respectively, and less than $13 \%$ as in control mice. At 72 hours, the ratios of sTLR ${ }^{+} \mathrm{CD} 1 \mathrm{~b}^{+} \mathrm{PMNs}$ were $7 \%, 5.5 \%$, and $9 \%$ in the infected mice, respectively, compared with $18 \%$ in control mice (Figure $4(\mathrm{~b})$ ). The ratios of sTLR9 ${ }^{+} \mathrm{CD}_{11 b^{-}}$PMNs constituted $52 \%, 53 \%$, and $68.5 \%$ of the $\mathrm{CD}^{-} 1 \mathrm{~b}^{-} \mathrm{PMNs}$ in the mice infected with $0.8,1.6$, and $2.4 \times$ $10^{8}$ CFUs of E. coli, respectively, for 18 hours $(P<0.05)$, compared with $3.5 \%$ in control mice, sharply decreased to $9 \%, 6 \%$, and $9.5 \%$ in the mice infected with $0.8,1.6$, and $2.4 \times 10^{8} \mathrm{CFUs}$ of E. coli, respectively, for 48 hours, compared with $8 \%$ in control mice, and reached $10 \%, 6 \%$, and $10 \%$ in the mice infected with $0.8,1.6$, and $2.4 \times 10^{8}$ CFUs of E. coli, respectively, for 72 hours, compared with $8 \%$ in control mice (Figure $4(\mathrm{c})$ )). These results indicated that $E$. coli could significantly induce the occurrence of both of the sTLR9 ${ }^{+} \mathrm{CD}_{11 b^{+}}$PMNs and sTLR ${ }^{+} \mathrm{CD} 1 \mathrm{~b}^{-}$PMNs in the peritoneal cavity at early stage of infection. Considering the fact that macrophages are the inflammatory cells which overlapped with the PMNs in the inflammatory sites, we also observed sTLR9 expression on macrophages in the PLCs. The results showed that the ratios of sTLR ${ }^{+}$macrophages constituted $5 \%, 6 \%$, and $6.7 \%$ $(P<0.05)$ of the macrophages in the mice infected with $0.8,1.6$, and $2.4 \times 10^{8}$ CFUs of E. coli, respectively, for 18 hours, compared with $3 \%$ in control mice, decreased to $0.9 \%$ 
$18 \mathrm{~h}$
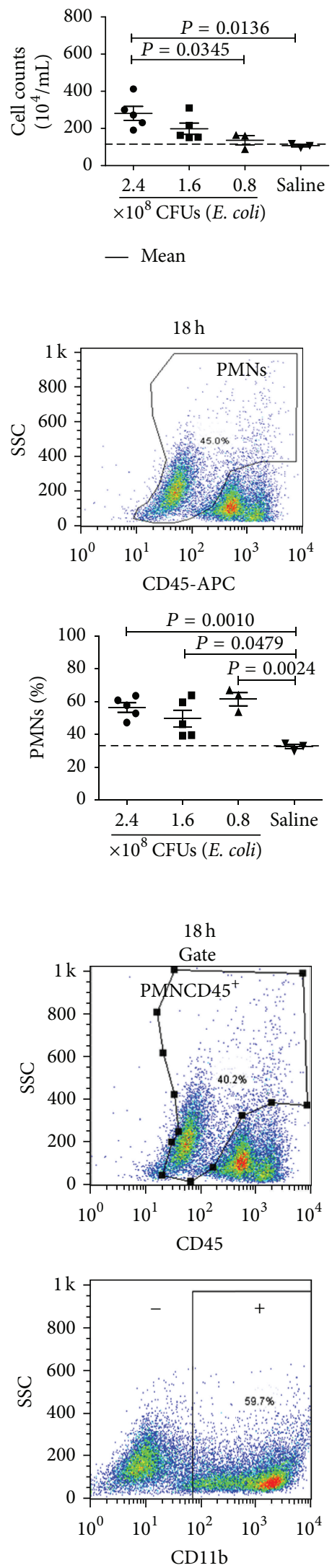

$48 \mathrm{~h}$
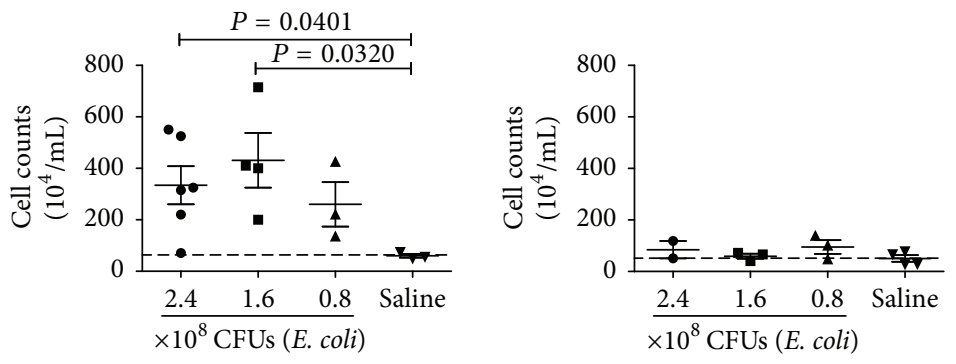

- Mean

- Mean

(a)
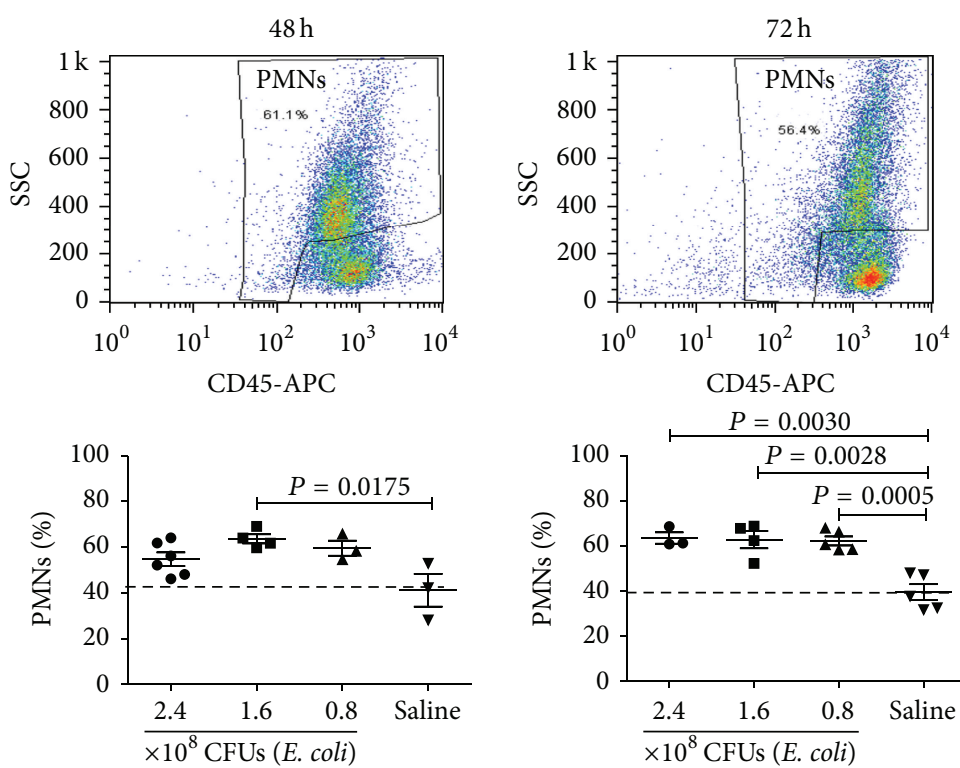

(b)
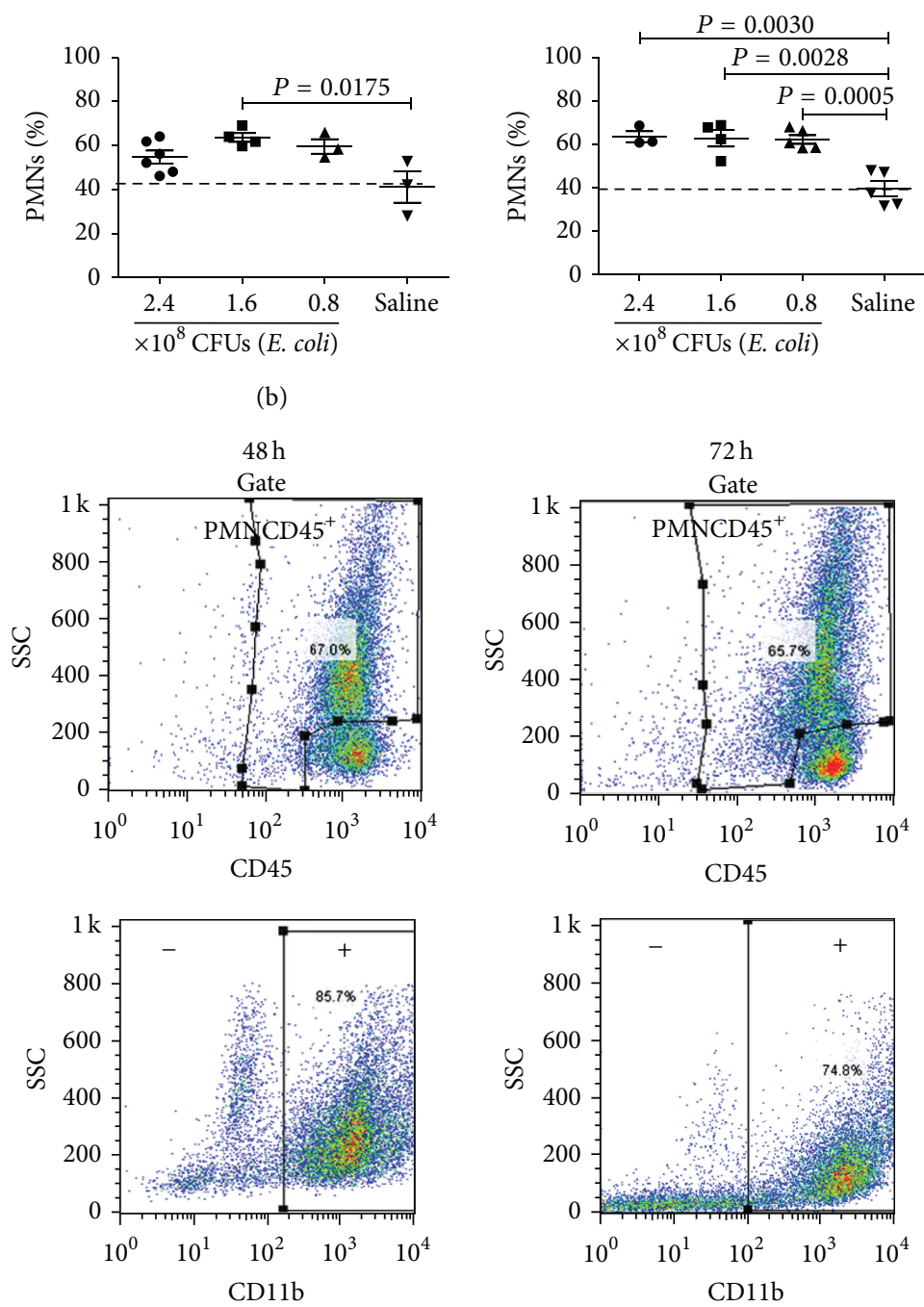

FIgUre 3: Continued. 

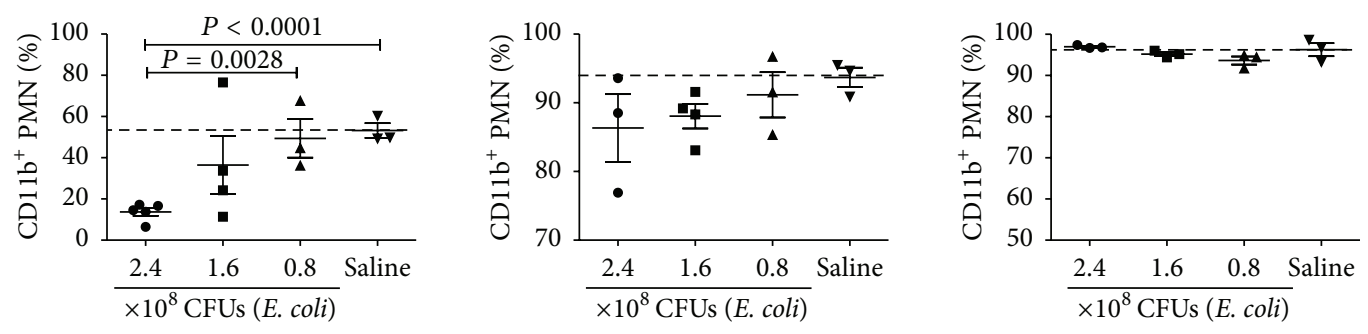

- Mean

- Mean

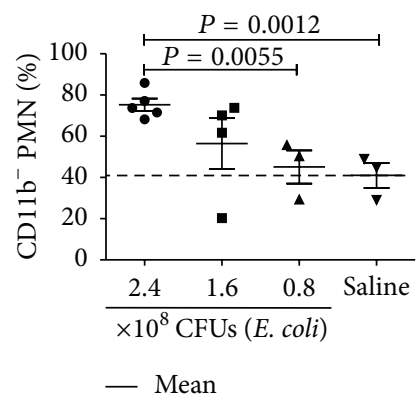

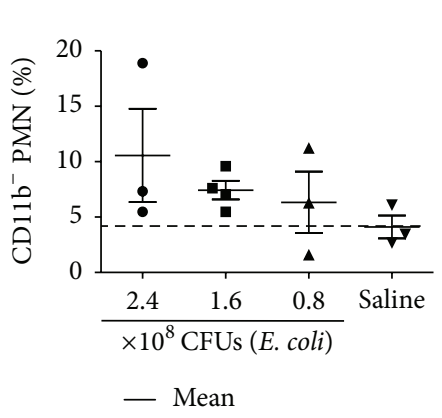

(c)

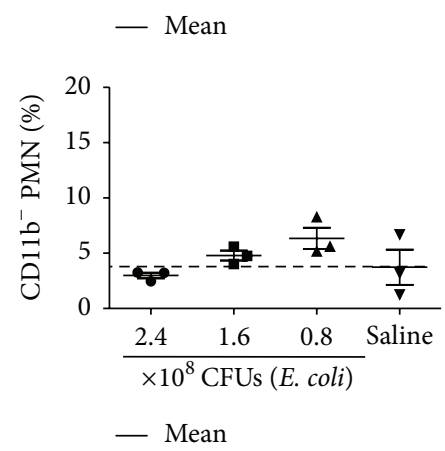

FIGURE 3: The numbers of PLCs and PMNs in mice infected intraperitoneally with E. coli. ICR mice were infected intraperitoneally with 3 doses of $E$. coli or received saline and sacrificed at 18, 48, and 72 hours to harvest their PLCs. The PLCs were counted immediately or stained with fluorescence-labeled mAbs of anti-CD45 and anti-CD11b followed by numerating with flow cytometry. (a) Numbers of PLCs. (b) Ratios of PMNs in PLCs. (c) Ratios of CD11b ${ }^{+}$PMNs and CD11b PMNs in the PMNs. Each point represents the data from one mouse.

$(P<0.05), 0.45 \%(P<0.05)$, and $3 \%$ in the mice infected with $0.8,1.6$, and $2.4 \times 10^{8} \mathrm{CFUs}$ of $E$. coli, respectively, for 48 hours, compared with $5 \%$ in control mice, and reached $4.8 \%, 2 \%(P<0.05)$, and $2.8 \%$ in the mice infected with $0.8,1.6$, and $2.4 \times 10^{8}$ CFUs of E. coli, respectively, for 72 hours, compared with $5.5 \%$ in control mice (Figure $4(d)$ ). These results indicated that, unlike PMNs, the macrophages barely express increased sTLR9 during septic peritonitis.

\subsection{Expression of Interleukin-17 (IL-17) in Neutrophils in PLCs} from Mice with Septic Peritonitis Induced by E. coli. In recent years, primary human and mouse neutrophils have been found to be able to display autocrine IL-17 activity that probably contributes to the etiology of microbial and inflammatory diseases [17]. To find whether the different subtype neutrophil derived IL-17 was involved in the development of septic peritonitis, we detected IL-17 expression in the CD11b ${ }^{+} \mathrm{PMNs}$ and $\mathrm{CD}_{11 b^{-}}$PMNs (Figure 5(a)) of the PLCs collected from the mice which were infected with $E$. coli or received saline (control mice). It was found that the ratios of $\mathrm{IL}-17^{+} \mathrm{CD} 11 \mathrm{~b}^{+}$ PMNs constituted $7 \%, 8.5 \%$, and $10 \%$ of the $\mathrm{CD}_{11 b^{+}}$PMNs in PLCs of the mice infected with $0.8,1.6$, and $2.4 \times 10^{8}$ CFUs of E. coli, respectively, for 18 hours $(P<0.05)$, compared with $25 \%$ in control mice, was $2 \%(P<0.05), 7.5 \%(P<$ 0.05 ), and $25.5 \%$ in the mice infected with $0.8,1.6$, and 2.4 $\times 10^{8}$ CFUs of $E$. coli, respectively, for 48 hours, compared with $25 \%$ in control mice, and reached $6 \%, 10 \%$, and $8 \%$ in the mice infected with $0.8,1.6$, and $2.4 \times 10^{8}$ CFUs of $E$. coli, respectively, for 72 hours $(P<0.05)$, compared with $27 \%$ in control mice (Figure 5(b)). Noticeably, the saline injection seemed to stimulate neutrophils to express IL-17. To confirm this, the PLCs were collected from the mice injected with saline at 18,48 , or 72 hours after the injection, respectively, and stained with fluorescence-labeled $\mathrm{mAb}$ against CD45, CD11b, and IL-17, followed by detection using flow cytometry. The control mice in this experiment were not injected with saline. We found that saline stimulation tended to induce IL17 expression (not statistically significant) with a big range of variation individually (data not shown). The ratios of the IL$17^{+} \mathrm{CD}_{11 b^{-}} \mathrm{PMN}$ were $5 \%, 4 \%$, and $3 \%$ of the CD11b ${ }^{-} \mathrm{PMNs}$ in the mice infected with $0.8,1.6$, and $2.4 \times 10^{8}$ CFUs of $E$. coli, respectively, for 18 hours, compared with $7 \%$ in control mice; $3 \%, 11 \%$, and $21.5 \%$ in the mice infected with $0.8,1.6$, and $2.4 \times$ $10^{8}$ CFUs of E. coli, respectively, for 48 hours, compared with $7 \%$ in control mice; and $7 \%, 8 \%$, and $13 \%$ in the mice infected with $0.8,1.6$, and $2.4 \times 10^{8} \mathrm{CFUs}$ of $E$. coli, respectively, for 72 hours, compared with $9 \%$ in control mice (Figure 5(c)). The results indicated that both of the $\mathrm{CD}_{11 b^{+}}$PMNs and the $\mathrm{CD}_{11 b^{-}} \mathrm{PMNs}$ could not increase IL-17 expression during the development of septic peritonitis in mice induced by $E$. coli. Also, as shown in Figure 5(d), macrophages could not increase the IL-17 expression in response to E. coli. Obviously, the results were in disagreement with the reports showing that PMNs could increase the production of IL-17 during bacterial infections. To validate the in vivo expression of IL17 in the PLCs, the PLCs pooled from the naïve mice were cocultured with E. coli at $1 \times 10^{5}$ CFUs, $1 \times 10^{6}$ CFUs or saline for 14 hours, and then with BFA for another 4 hours. The cultured cells were harvested, stained with FITC-labeled antiIL-17 mAb, and detected by flow cytometry. As shown in Figure 5(e), E. coli could significantly increase IL-17 ${ }^{+}$PLCs of the naïve mice, indicating that $E$. coli could stimulate 

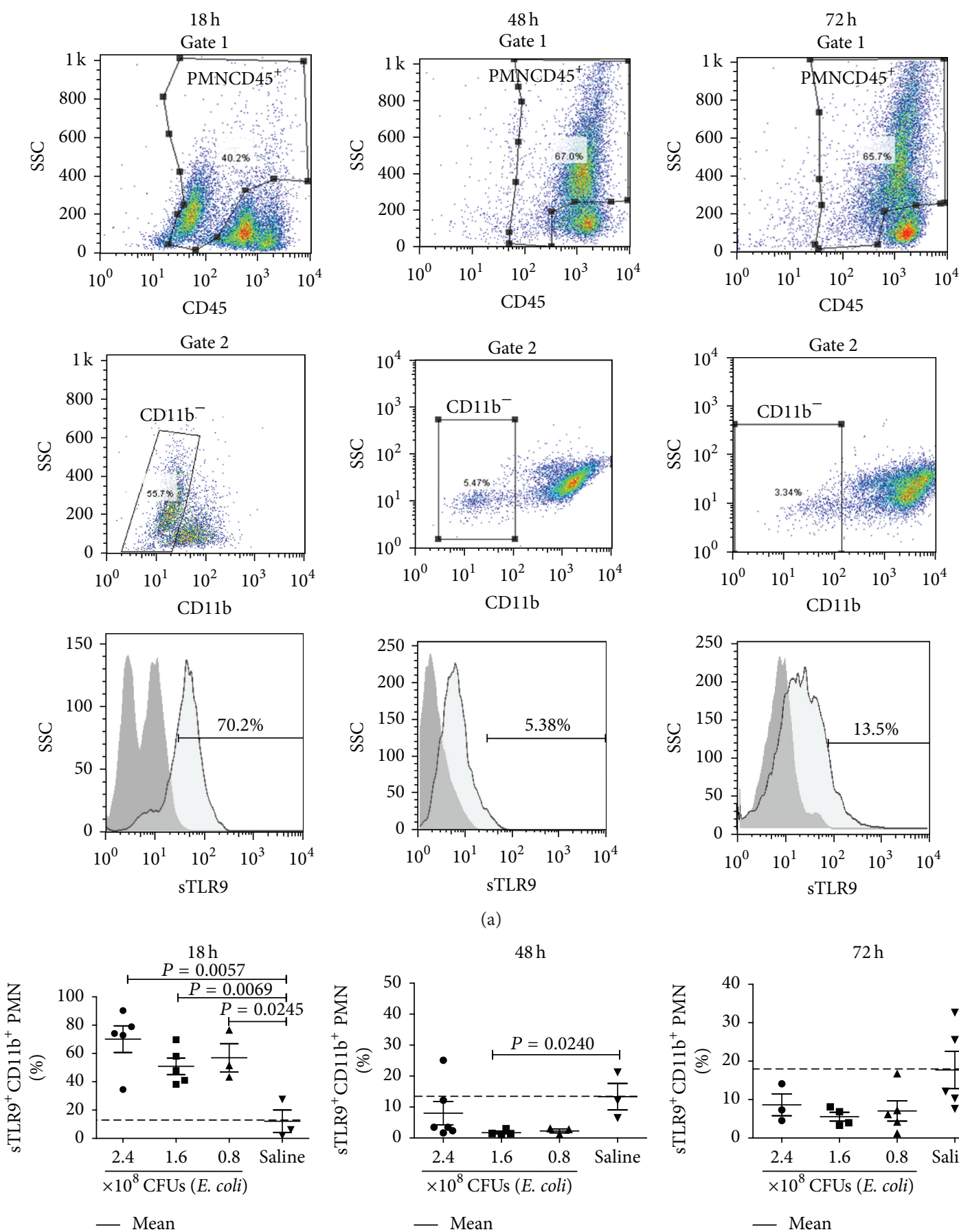

(a)
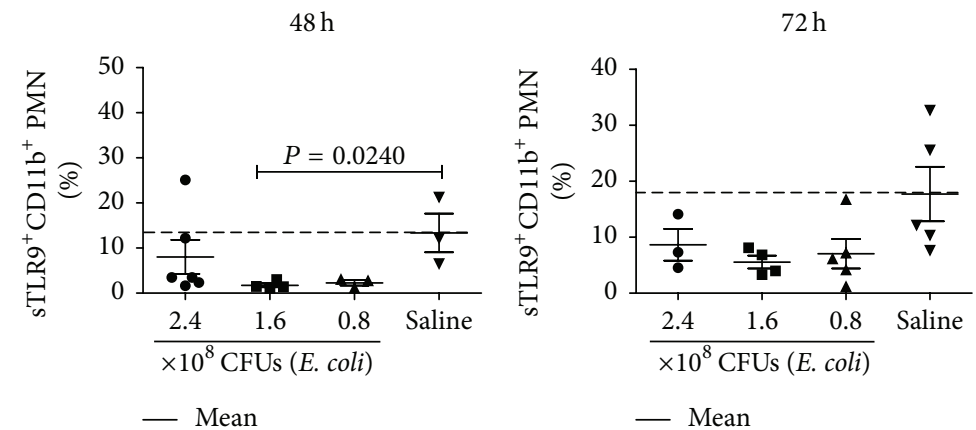

(b)

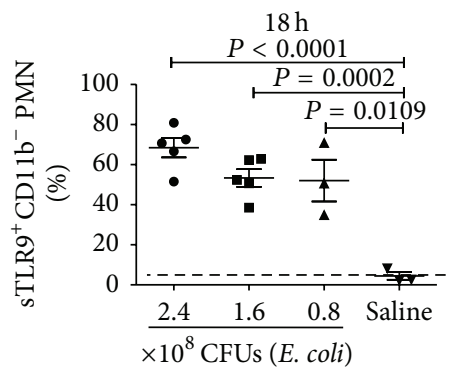

$48 \mathrm{~h}$
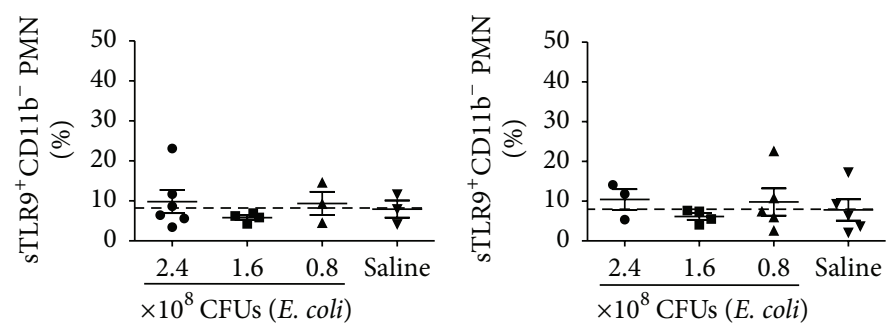

(c)

FIGURE 4: Continued. 

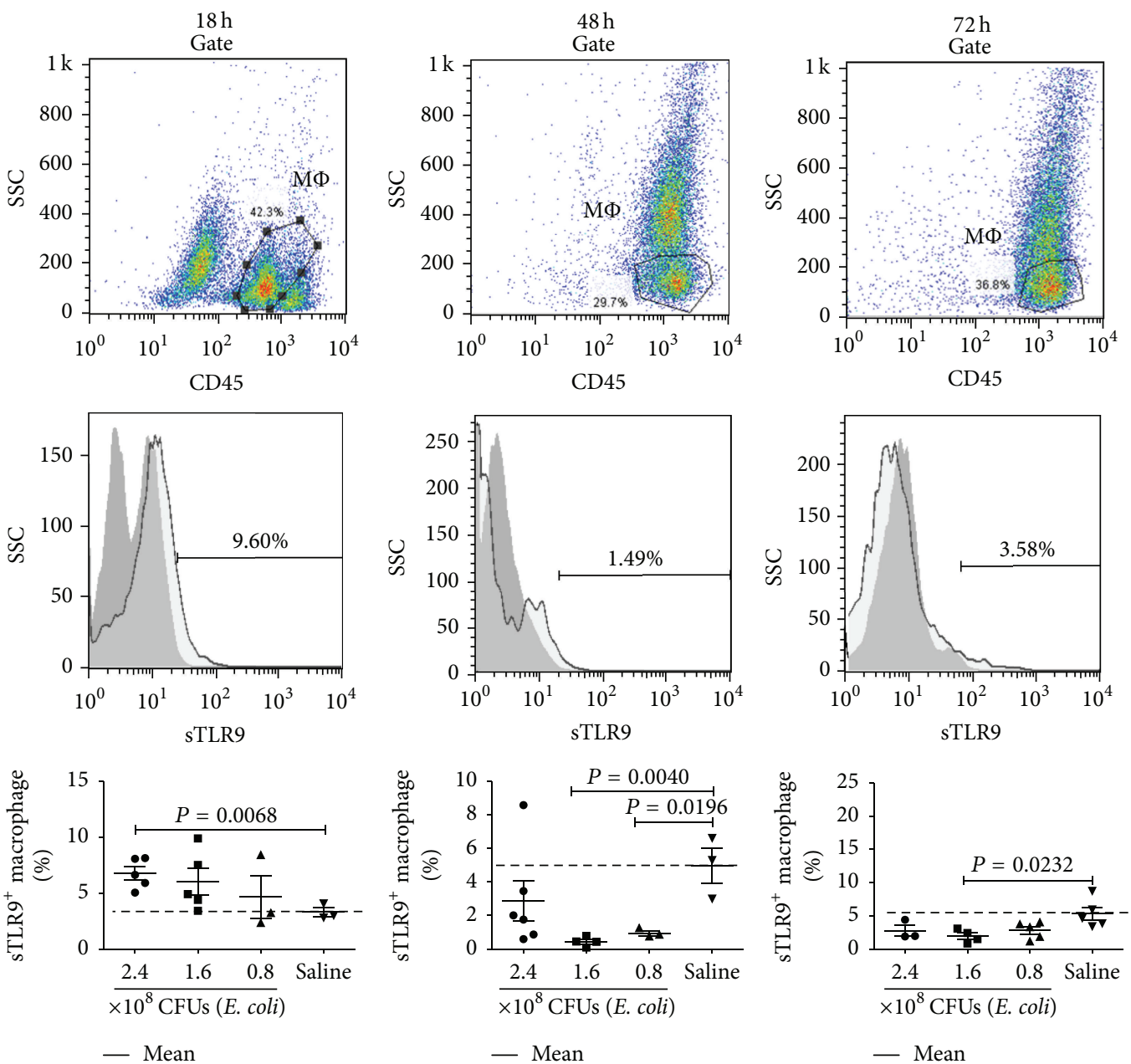

(d)

FIGURE 4: The ratios of sTLR9 ${ }^{+}$PMNs and macrophages in PLCs from mice infected intraperitoneally with $E$. coli. ICR mice were infected intraperitoneally with 3 doses of $E$. coli or received saline and sacrificed at 18, 48, and 72 hours to harvest their PLCs. The PLCs were stained with fluorescence-labeled mAb of anti-CD45, anti-CD11b, and anti-TLR9 followed by detection with flow cytometry. (a) Gates of the PMNs from the CD $45^{+}$PLCs followed by gating CD11b ${ }^{+}$PMNs or CD11b ${ }^{-}$PMNs from the PMNs. (b) Ratios of sTLR9 ${ }^{+}$PMNs in CD11b ${ }^{+}$PMNs. (c) Ratios of sTLR9 ${ }^{+}$PMNs in CD11b ${ }^{-}$PMNs. (d) Ratios of sTLR9 ${ }^{+}$macrophages. Each point represents the data from one mouse.

the PLCs to express IL-17. To clarify this, we set up an experiment to detect IL-17 mRNA expression in the PLCs from the mice infected with $0.8,1.6$, and $2.4 \times 10^{8}$ CFUs of E. coli for 18 hours, respectively, or from the control mice and found that the IL-17 mRNA levels in the mice infected with 3 doses of $E$. coli were significantly elevated in a dose dependent manner (Figure 5(f)). Next we sorted $\mathrm{CD}^{+}$cells and $\mathrm{CD}^{-} \mathrm{CD}^{-} 4^{-} \mathrm{CD}_{11 b^{+}}$cells from the PLCs of the mice which were infected with $E$. coli or received saline for 18 hours, detected their IL-17 mRNA expression by qRT-PCR, and found that IL-17 mRNA levels were significantly increased in both of the $\mathrm{CD}^{+} \mathrm{T}$ cells $(P=0.0006)$ and the $\mathrm{CD}^{-} \mathrm{CD}^{-} 4^{-} \mathrm{CD} 1 \mathrm{~b}^{+}$cells $(P=0.0434)$ in the PLCs from the $E$. coli infected mice. Comparatively, the IL-17 mRNA levels in the $\mathrm{CD}^{+} \mathrm{T}$ cells were much higher than those in the $\mathrm{CD}^{-} \mathrm{CD}^{-} 4^{-} \mathrm{CD}_{11 b^{+}}$neutrophils. The result indicated that both of $\mathrm{T}$ cells and PMNs were the IL-17 producers in the peritoneal cavity during the development of septic peritonitis (Figure 5(g)). The result suggests that the PLCs from the infected mice did express IL-17 and IL-17 in the PMNs might be secreted out during the development of septic peritonitis.

3.6. Correlation of sTLR9 Expression with IL-17 Production in Neutrophils at Early Stage of E. coli Induced Septic Peritonitis in Mice. To find the possible correlation between the production of IL-17 and the expression of sTLR9 in/on the PMNs and macrophages in peritoneal cavity of the mice during septic peritonitis, we harvested the PLCs from the mice infected with $0.8,1.6$, and $2.4 \times 10^{8} \mathrm{CFUs}$ of $E$. coli, respectively, at early stage of 8 hours after infection and detected their expression of IL-17 and sTLR9. The saline injected mice were as controls. The expression was represented by mean fluorescence intensity (MFI) to emphasize the increased expression of IL17 and sTLR9 per cell. As shown in Figure 6, IL-17 expression 

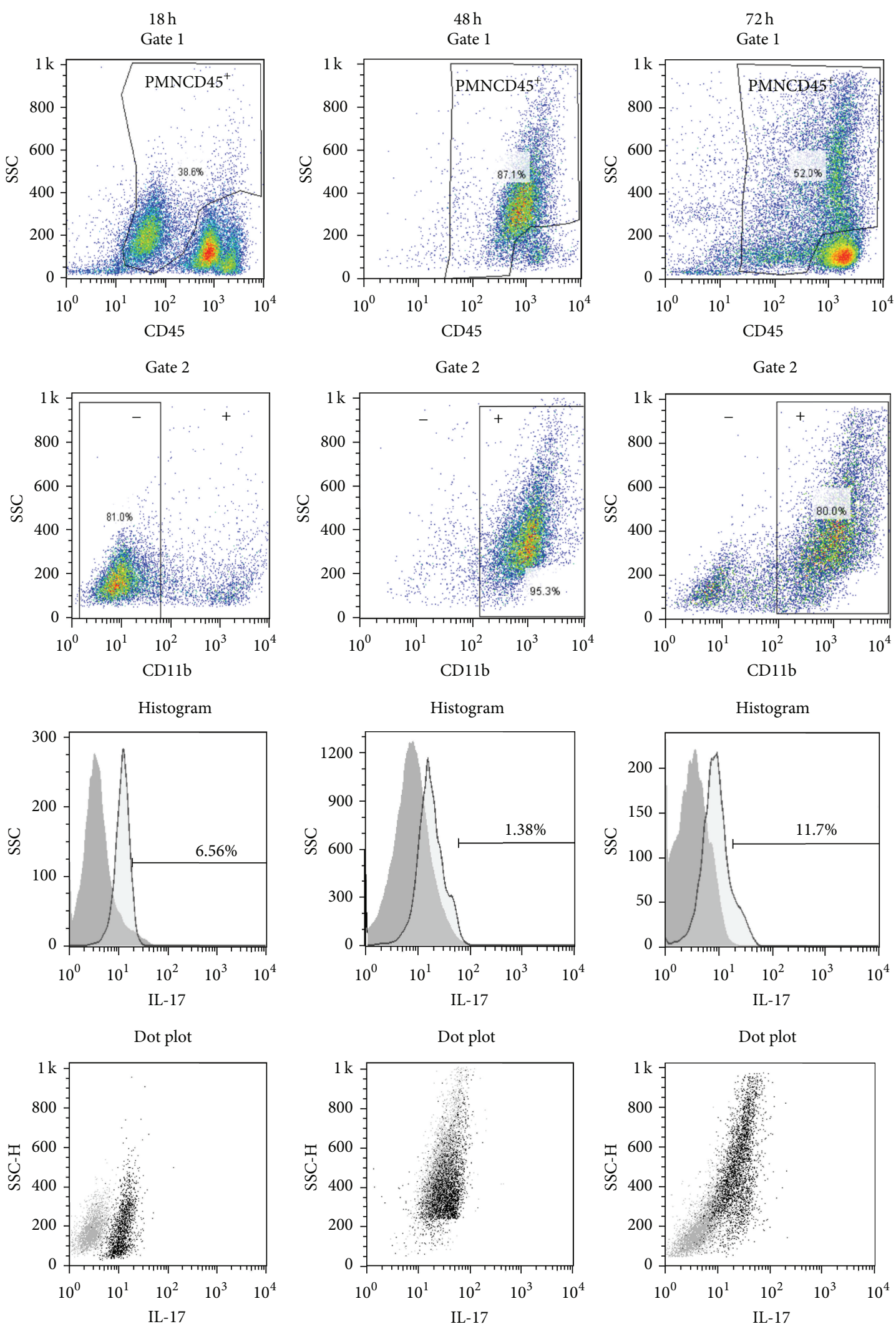

Control

Control

Control

Sample

Sample

(a)

Figure 5: Continued. 


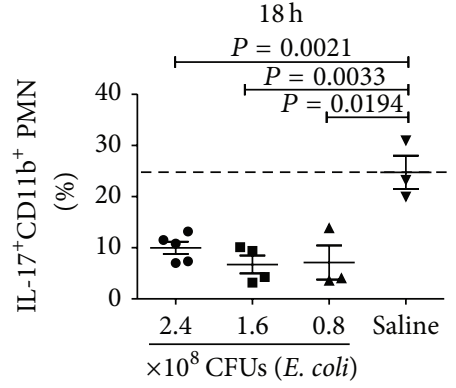

- Mean
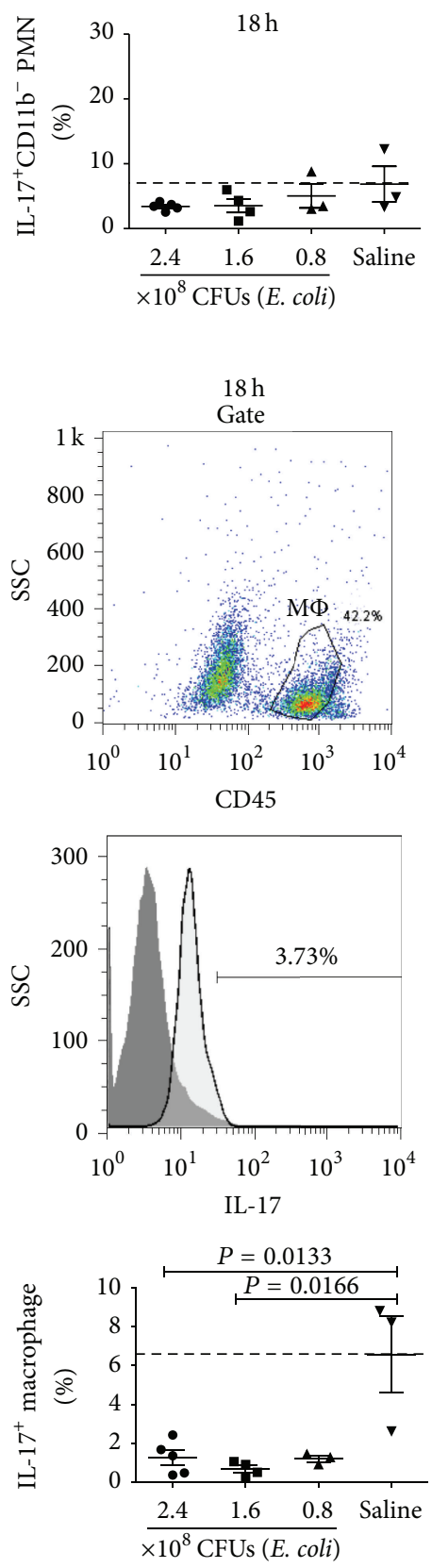

— Mean

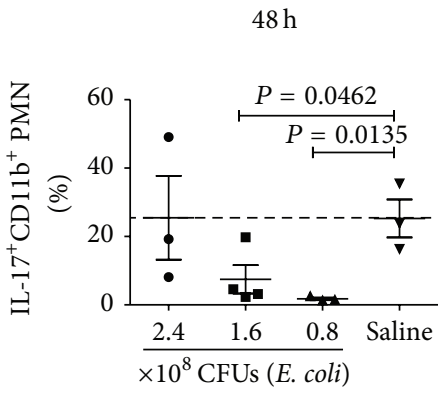

- Mean

(b)

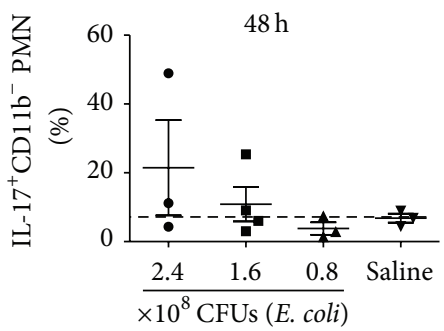

(c)
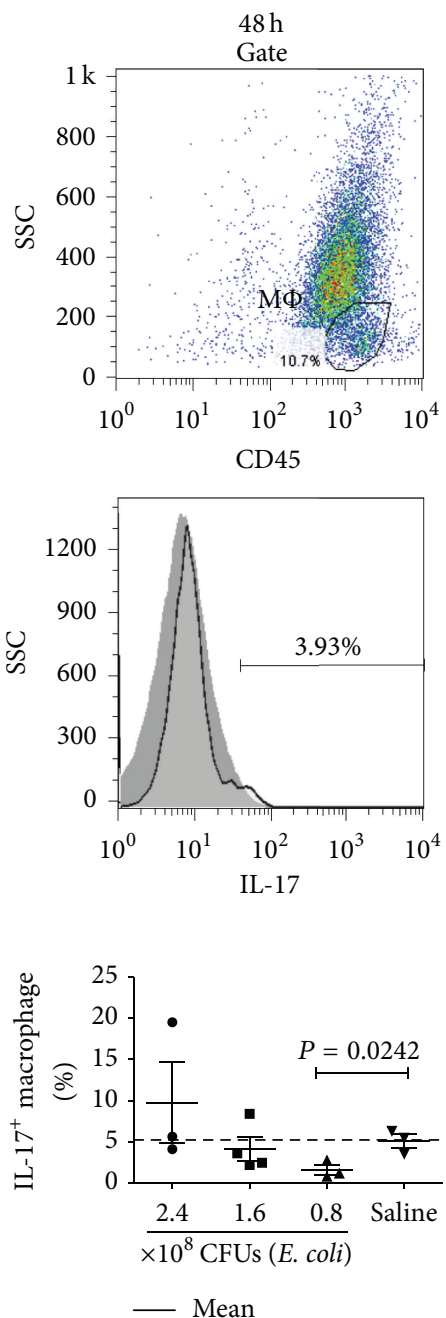

(d)

Figure 5: Continued.
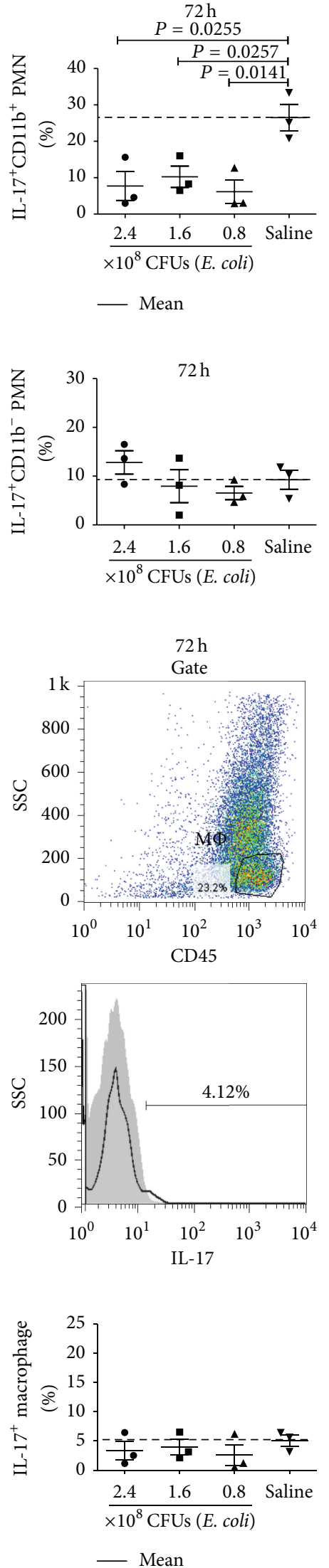


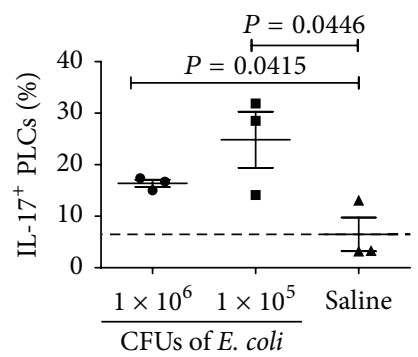

(e)

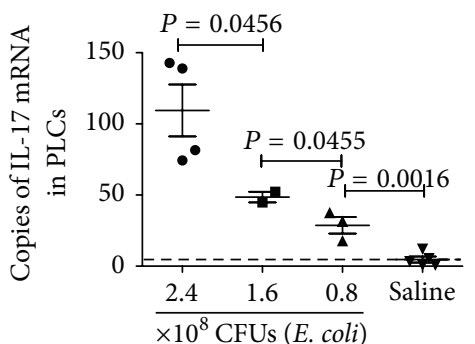

(f)

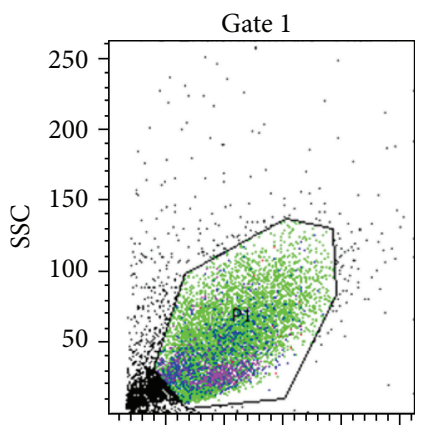

$\begin{array}{llllll}50 \quad 100 & 150 & 200 & 250\end{array}$

FSC
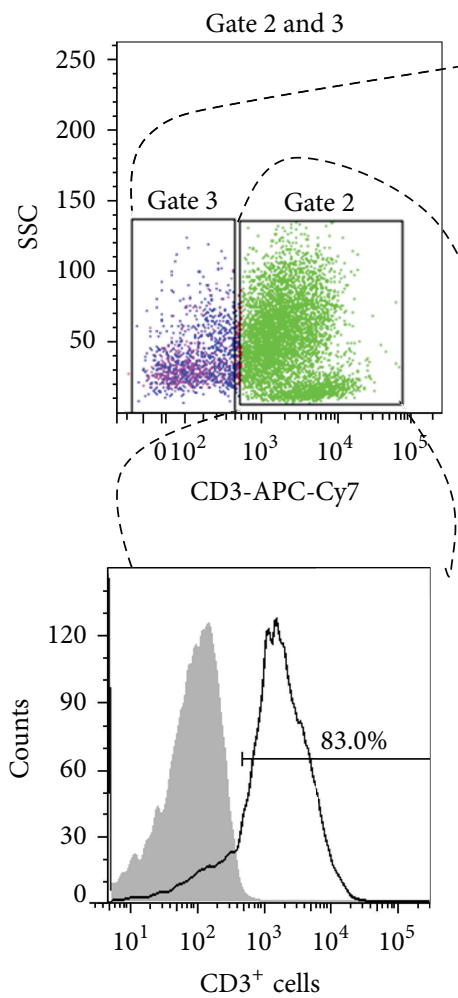

IL-17 mRNA in sorted cells

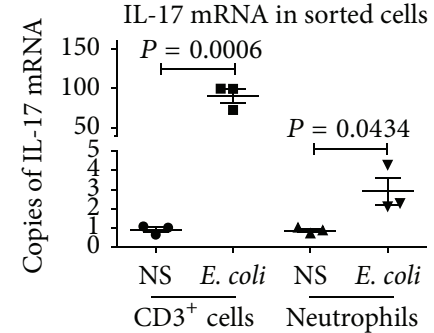

$\mathrm{CD}^{-} \mathrm{CD} 14^{-} \mathrm{CD} 11 \mathrm{~b}^{+}$

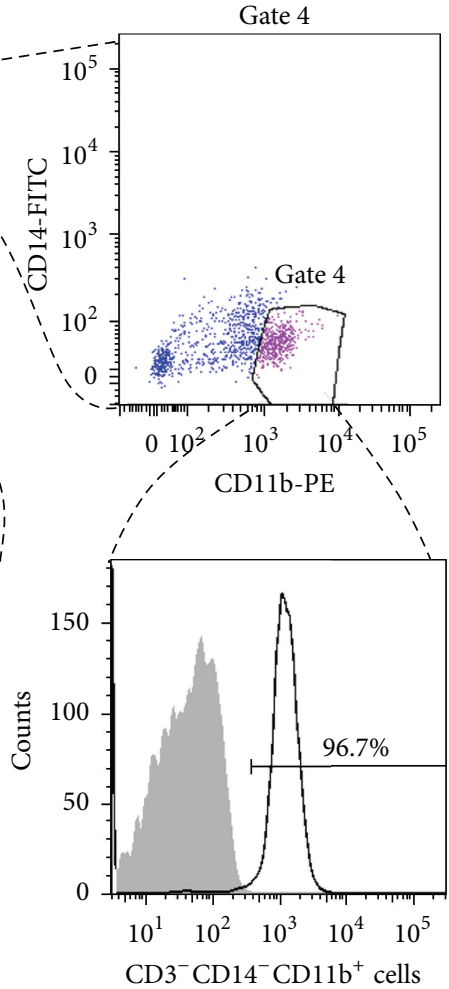

(g)

FIgURE 5: The ratios of IL-17 ${ }^{+}$PMNs and macrophages in PLCs from mice infected with E. coli intraperitoneally. ICR mice were infected with E. coli at 3 doses or received saline and sacrificed at 18,48, and 72 hours to harvest their PLCs. The PLCs were stained with fluorescence-labeled $\mathrm{mAb}$ of anti-CD45, anti-CD11b, and anti-IL-17, followed by detection with flow cytometry or lysed to isolate total RNA for amplifying IL-17 mRNA by qPCR. (a) PMNs gated from the CD $45^{+}$PLCs (gate 1) and CD11b ${ }^{+}$PMNs or CD11b ${ }^{-}$PMNs from the gated PMNs (gate 2 ). (b) Ratios of IL-17 $7^{+}$PMNs in CD11b ${ }^{+}$PMNs. (c) Ratios of IL-17 ${ }^{+}$PMNs in CD11b PMNs. (d) Ratios of IL-17 ${ }^{+}$macrophages. (e) Percentages of $\mathrm{IL}^{+}{ }^{+}$PLCs in the PLCs cocultured with E. coli. (f) Copies of IL-17 mRNA in the PLCs. Each point represents the data from one mouse. (g) IL-17 mRNA expression in sorted $\mathrm{CD}^{+}$cells or $\mathrm{CD}^{-} \mathrm{CD}^{-} 4^{-} \mathrm{CD} 11 \mathrm{~b}^{+}$neutrophils. 


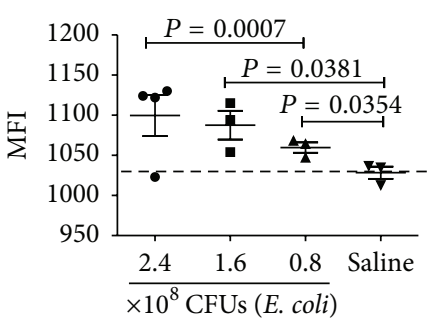

(a)

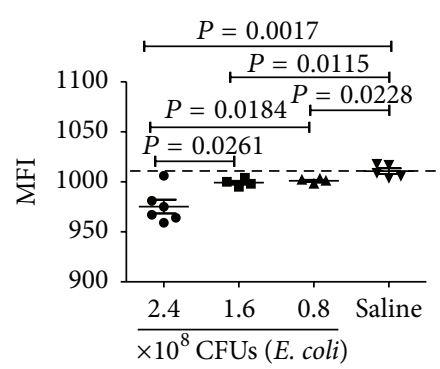

(d)

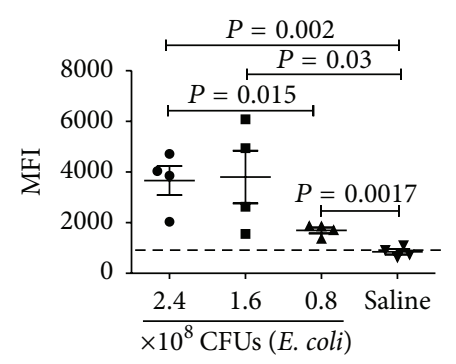

(g)

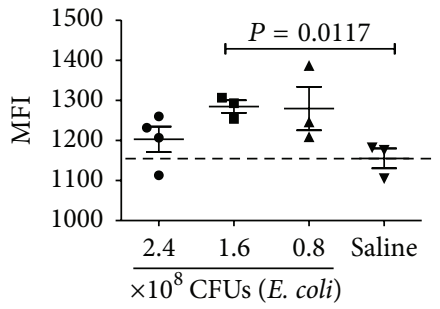

(b)

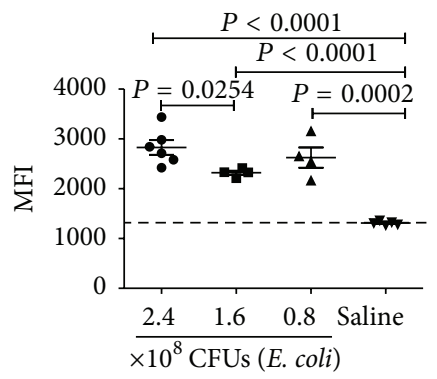

(e)

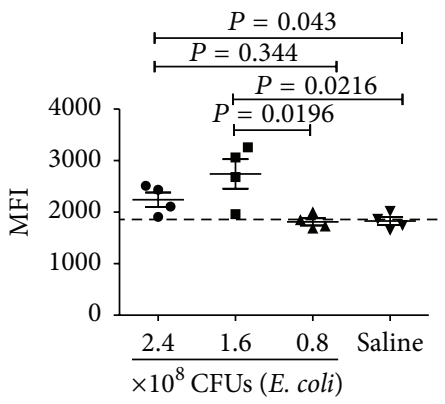

(h)

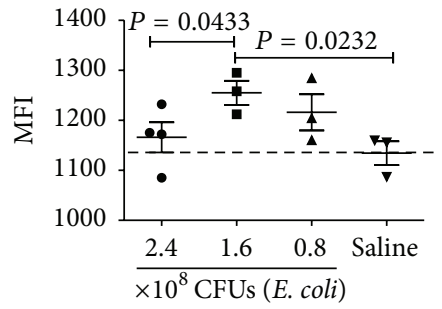

(c)

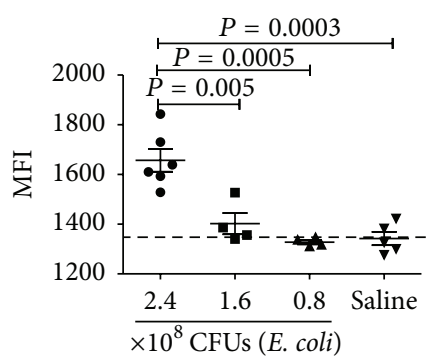

(f)

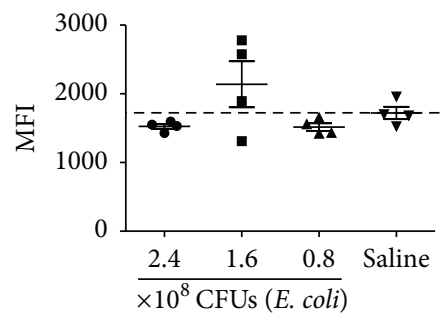

(i)

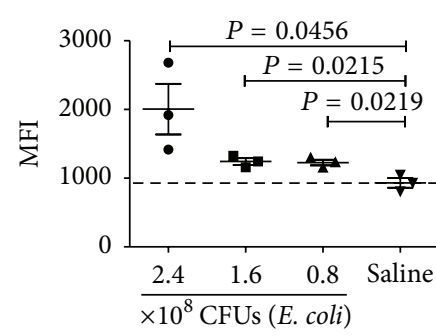

(j)

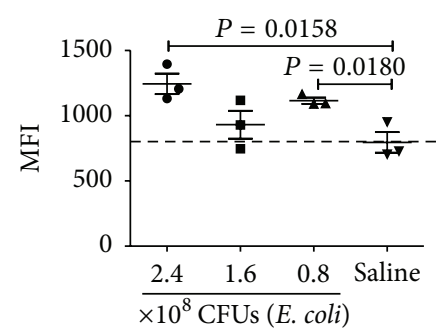

(k)

Figure 6: The expression of IL-17 and sTLR9 in/on PMNs, macrophages, and T cells in the PLCs from mice infected with E. coli intraperitoneally at early stage after infection. ICR mice which were infected with $E$. coli at 3 doses or received saline were sacrificed at 8 hours after infection for harvesting their PLCs. The PLCs were stained with fluorescence-labeled mAb of anti-CD45, anti-CD11b, anti-IL17, anti-sTLR9, anti-CD3, and anti-Ly6G, followed by detection with flow cytometry. The expression levels of IL-17 and sTLR9 in various cells of the PLCs were indicated by mean fluorescence intensity (MFI). (a) IL-17 in CD11b PMNs. (b) IL-17 in CD11b ${ }^{+}$PMNs. (c) IL-17 in macrophages. (d) sTLR9 on CD11b ${ }^{-}$PMNs. (e) sTLR9 on CD11b ${ }^{+}$PMNs. (f) sTLR9 on macrophages. (g) sTLR9 on CD11 ${ }^{+}$Ly6G ${ }^{+}$PMNs. (h) IL-17 in CD11b ${ }^{+}$Ly6G ${ }^{+}$PMNs. (i) IL-17 in sTLR9 ${ }^{+}$CD11b $^{+}$Ly6G ${ }^{+}$PMNs. (j) IL-17 in CD3 ${ }^{+}$PLCs. (k) IL-17 in CD3 ${ }^{-}$CD11b $^{+}$PMNs. Each point represents the data from one mouse.

was significantly upregulated in the $\mathrm{CD}^{-11 b^{-}} \mathrm{PMN}$ from the infected mice and their levels were positively correlated with the doses of E. coli (Figure 6(a)), while the upregulated IL17 expression was only observed in the CD11b ${ }^{+}$PMNs or macrophages from the mice infected with $0.8 \times 10^{8}$ CFUs and $1.6 \times 10^{8} \mathrm{CFUs}$ of $E$. coli. The highest dose of $E$. coli could not induce the highest levels of IL-17 in the CD11b
PMNs or macrophages after infection for 8 hours (Figures 6(b) and 6(c)). This result reveals that IL-17 may be mainly derived from $\mathrm{CD}^{-} \mathrm{b}^{-} \mathrm{PMN}$ and secrete out earlier during bacterial infection in mice infected with high dose of $E$. coli. In parallel, we also tested the expression of sTLR9 on PMNs and macrophages and found that sTLR9 expression was significantly downregulated in the $\mathrm{CD}_{11 b^{-}} \mathrm{PMNs}$ from 
the infected mice and the lowest downregulation happened in the $\mathrm{CD}_{11 b^{-}}$PMNs from the mice infected with $2.4 \times 10^{8} \mathrm{CFUs}$ of E. coli (Figure 6(d)). In contrast, sTLR9 expression was significantly upregulated in the $\mathrm{CD}_{11 b^{+}}$PMNs from the infected mice (Figure 6(e)). Interestingly, the significantly upregulated expression of sTLR9 was observed also in the macrophages from the mice infected with $2.4 \times 10^{8} \mathrm{CFUs}$ of E. coli (Figure 6(f)). To validate whether other types of cells in the PLCs also expressed IL-17 and sTLR9, the PLCs from mice infected with $E$. coli for 8 hours were stained with fluorescence-labeled mAbs against Ly6G, CD11b, IL17, or TLR9 and then analyzed by flow cytometry. The results showed that $E$. coli infection significantly increased IL-17 expressing $\mathrm{CD}_{11 b^{+}} \mathrm{Ly}_{6 \mathrm{G}}{ }^{+}$neutrophils (Figure 6(h)) as well as sTLR9 expressing $\mathrm{CD}_{11 b^{+}} \mathrm{Ly}_{6 \mathrm{G}}{ }^{+}$neutrophils (Figure 6(g)) in a dose dependent manner but could not increase IL-17 expression in the sTLR9 ${ }^{+} \mathrm{CD}_{11 b}{ }^{+} \mathrm{Ly}_{6 \mathrm{G}}{ }^{+}$neutrophils (Figure 6(i)) at the time point. In parallel, the PLCs were stained with fluorescence-labeled $\mathrm{mAbs}$ against CD3, CD11b, and IL-17 and analyzed. It was found that both $\mathrm{CD}^{+}$ $\mathrm{T}$ cells (Figure 6(j)) in the PLCs and $\mathrm{CD}^{-} \mathrm{CD}^{-} 1 \mathrm{~b}^{+}$PMNs (Figure 6(k)) increased their IL-17 expression in response to the infection with E. coli for 8 hours. This result indicates that, at early stage, sTLR9 may be mainly expressed on CD11b ${ }^{+}$ PMNs in PLCs of the mice infected with E. coli, and with the infection progression, macrophages may become successors to replace the $\mathrm{CD}_{11 \mathrm{~b}^{+}}$PMNs as the major sTLR9 ${ }^{+}$cells.

\section{Discussion}

In this study, we tried to investigate the correlation of TLR9 expression with IL-17 production in PMNs during septic peritonitis and found that both sTLR9 and IL-7 could be expressed in the PMNs infiltrated into the peritoneal cavity of the mice infected with E. coli. At early stage of the infection, sTLR9 was increasingly expressed in the infiltrated CD1lb ${ }^{+}$ PMNs, and IL-17 was increasingly expressed in both of the $\mathrm{CD}_{11 b^{-}}$PMNs and CD11b ${ }^{+}$PMNs. IL-17 expression in $\mathrm{CD} 1 \mathrm{~b}^{-}$PMNs was positively correlated with the doses of $E$. coli. When infected with the highest dose of E. coli $(2.4 \times$ $\left.10^{8} \mathrm{CFUs}\right)$, IL-17 was increasingly expressed and sTLR9 was decreasingly expressed in/on the CD11b ${ }^{-} \mathrm{PMN}$. When infected with the lowest dose of E. coli $\left(0.8 \times 10^{8} \mathrm{CFUs}\right)$, both IL-17 and sTLR9 were increasingly expressed in CD1lb ${ }^{+}$ PMNs. Furthermore, we stained the PLCs with both CD11b

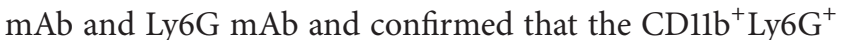
PMNs in the PLCs could increase their expression of both IL17 and sTLR9 in response to $E$. coli infection. Taken together, with the fact that highest dose of E. coli $\left(2.4 \times 10^{8} \mathrm{CFUs}\right)$ was the most deadly and the lowest dose of $E$. coli was the least deadly to the mice with septic peritonitis, we may deduce that increased expression of both sTLR9 and IL-17 in CD11b ${ }^{+}$ PMNs might benefit the survival of the mice with septic peritonitis and that the decreased expression of sTLR9 and increased expression of IL-17 in CD11b ${ }^{-}$PMNs may be detrimental to the mice.

In recent years, PMNs have been found to be able to express sTLR9 which engage PAMPs, such as bacterial DNA generated during infection, and damage-associated molecular patterns (DAMPs), such as mitochondrial DNA released from necrotic cells during sterile inflammation. The engagement, if intense, can prime PMNs to release massively produced cytokines [22], leading to sepsis or systemic inflammatory response syndrome (SIRS) [12]. In the present work, we found that the ratios of the sTLR $^{+} \mathrm{CD} 1 \mathrm{~b}^{+} \mathrm{PMNs}$ and sTLR9 $^{+} \mathrm{CD} 1 \mathrm{~b}^{-} \mathrm{PMNs}^{+}$were significantly increased in the infiltrated $\mathrm{CD} 1 \mathrm{~b}^{+}$PMNs and $\mathrm{CD} 1 \mathrm{~b}^{-} \mathrm{PMNs}$ of the mice infected with $E$. coli for 18 hours, respectively. At this stage, we observed that a plenty of $E$. coli coexisted with the PMNs. When observed at 48 hours and 72 hours after infection, the ratios of both of the sTLR ${ }^{+} \mathrm{CD}^{+} 1 \mathrm{~b}^{+} \mathrm{PMNs}$ and sTLR9 $^{+} \mathrm{CD} 1 \mathrm{~b}^{-} \mathrm{PMNs}$ were sharply decreased to the levels as those in saline control. Accompanying with the decrease, E. coli underwent disappearing. Possibly, the increased

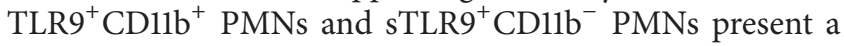
rapid innate immune response of the PMNs to bacterial invasion at the early stage of infection. PMNs armed with sTLR9 were demonstrated to be able to sense extracellular ligands and consequently initiate TLR9 mediated signaling in an intracellular TLR9 independent way. The response could offer a rescue mechanism for PMN activation when pathogen derived TLR9 ligands cannot reach the endosome in the early stage of infection [10]. Practically, the increased expression of sTLR9 on PMNs may be a proinflammatory activation marker [10] and sTLR9 ${ }^{+}$PMN should benefit antibacterial defense during infection, evidenced by the following: (1) TLR9 agonists, if they exist, could activate sTLR9 ${ }^{+}$PMN, not TLR9-deficient PMNs, to upregulate CD11b and secrete MIP2 and IL-8 (CXCL8) [10]; (2) sTLR9 ${ }^{+}$PMNs are involved in inducing the rapid inflammation which is needed in the initial phase of bacterial infection by secreting antimicrobial peptides and elastases [9]; (3) encountering microbial DNA, sTLR9 signaling is able to activate PMNs, and the activated PMN increases sTLR9 expression [9]. However, it is worthy to note that sTLR9 ${ }^{+}$PMNs could be culprit for causing more severe pathological consequences. For instance, bacterial DNA or formulated peptides released following sepsis were reported to activate p38 MAP kinase through binding sTLR9 on PMNs, leading to acute lung injury which is characterized by protein-rich pulmonary oedema (swelling) and accumulation of large numbers of PMNs in the lungs [13].

It is well established that PMNs, as the firstly recruited inflammatory cells in infection sites, are IL-17 producing cells. IL-17 secreted from PMNs induces the release of proinflammatory factors from mesenchymal and myeloid cells, recruiting additional PMNs [15]. In addition to PMNs, macrophages located in the epithelial barriers are also important sources of IL-17. In this study, we initially found that the average ratios of the $\mathrm{IL}_{17}{ }^{+} \mathrm{CD} 11 \mathrm{~b}^{+}$PMNs and $\mathrm{IL} 17^{+}$macrophages were significantly decreased in the PLCs at 18, 48, and 72 hours in the mice infected with 3 doses of E. coli. Seemingly, the CD11b ${ }^{+}$ PMNs and macrophages, in response to the peritoneal infection, could not produce increased IL-17. However, when checking mRNA expression, we found significantly upregulated IL-17 mRNA in the PLCs from the mice infected with E. coli for 18 hours (Figure 5(e)). The data imply that the infiltrated cells in peritoneal cavity of the mice infected with $E$. coli 
could produce IL-17 and the produced IL-17 may promptly secrete out the cells, therefore resulting in the decreased ratios of $\mathrm{IL}_{17} 7^{+} \mathrm{CD} 11 \mathrm{~b}^{+}$PMNs and $\mathrm{IL}_{1} 7^{+}$macrophages. To clarify this, we harvested the PLCs from the mice infected with E. coli at early stage of 8 hours after infection and detected their IL17 levels which were expressed as mean fluorescence intensity (MFI). By doing this, we found that both of the CD11b ${ }^{-}$PMNs and $\mathrm{CD}_{11 \mathrm{~b}^{+}}$PMNs obviously produced IL-17 in the early stage of the peritoneal infection caused by E. coli. To confirm this, we set up another experiment in which the PLCs were harvested at 12 and 16 hours after the infection, cultured with $\mathrm{BFA}$, a protein transport inhibitor capable of retaining the produced cytokines inside the cells, for additional 4 hours, and then detected their IL-17 expression. We found that the $\mathrm{BFA}$ in vitro treatment significantly increased the average ratios of the $\mathrm{IL}_{17} \mathrm{CD}^{+} 11 \mathrm{~b}^{+}$PMNs in $\mathrm{CD} 11 \mathrm{~b}^{+} \mathrm{PMNs}$ and $\mathrm{IL}_{17}{ }^{+}$ macrophages in macrophages (data not shown). The results support the assumption that produced IL-17 in CD11b ${ }^{+} \mathrm{PMNs}$ and macrophages could be secreted out promptly in response to $E$. coli at the early stage of septic peritonitis in mice. Theoretically, deducing based on the published data, IL-17 derived from $\mathrm{CD} 1 \mathrm{~b}^{+}$PMNs and macrophages may initiate a response to induce chemokines which in turn recruit more PMNs $[23,24]$ to the site of infection $[18,25]$. The new comer PMNs join the fighting against invaded bacteria, resulting in more IL-17 $[16,17]$. In addition to the PMNs, macrophages could be recruited by IL-17 [20, 26], specifically by $\mathrm{CD}_{11 \mathrm{~b}^{+}}$PMNs derived IL-17. IL-17 could recruit more macrophages into peritoneal cavity during septic peritonitis. The increased macrophages could produce more IL-17 to join the $\mathrm{CD}_{11 b^{+}}$PMNs produced IL-17, playing a defense role in fighting bacterial infection and reducing mortality of mice with septic peritonitis [27]. In addition to the PMNs and macrophages, $\gamma \delta \mathrm{T}$ cells were found as a major producer of IL-17 in the mice with experimental sepsis induced by CLP; $\gamma \delta$ T cell-derived IL-17 could promote production of proinflammatory mediators, resulting in enhanced lethality [28]. Compatibly, T cells, in this study, were confirmed to be involved in the development of septic peritonitis in mice by the evidence that (1) the IL-17 expression was increased in the $\mathrm{CD}^{+}$cells of the PLCs from the mice infected with $E$. coli and (2) IL-17 mRNA levels were significantly increased in the sorted $\mathrm{CD}^{+}$cells in the PLCs from the mice infected with E. coli. Furthermore, IL-17 expression was obviously increased in the sorted CD3 ${ }^{-} \mathrm{CD}_{11 b^{+}}$PMNs in the PLCs from the mice infected with E. coli. Together, these data suggest that the PMNs, like T cells, do express IL-17 as a response to bacterial infection during septic peritonitis. Although $\mathrm{CD}^{+}$cells were one of the major producers of IL-17 during the development of septic peritonitis, probably, neutrophils might produce more IL-17 compared to $\mathrm{CD}^{+}$cells because the neutrophils, as we found in this study, could constitute up to $70 \%$ of the PLCs (Figure 3(b)), whereas $\mathrm{CD}^{+}$cells only constituted $10-15 \%$ of the PLCs (data not shown). Interestingly, sTLR9 ${ }^{-} \mathrm{CD}_{11 b^{+}} \mathrm{Ly}_{6 \mathrm{G}}{ }^{+}$PMNs, not sTLR9 ${ }^{+} \mathrm{CD}_{11 b^{+}} \mathrm{Ly}_{6 \mathrm{G}^{+}}$PMNs, were found to be able to increase their IL-17 expression during septic peritonitis.

Interestingly, we found a type of giant cells with increasing numbers in the PLCs from the mice infected with E. coli up to
$1.6 \times 10^{8}$ CFUs. Morphologically, the giant cells (Figure 2(a)) could be the PMNs with a changed lobulated nucleus located near to cell membrane, being at least 4 times larger than the regular PMNs. Obviously, the giant cells are the newly described cells and have several facets worthy of note. (1) Kinetically, the giant cells only appeared at the early stage of the infection and were not observed in the PLCs of the mice infected for 48 and 72 hours. (2) The giant cells only occurred in the PLCs of the severely infected mice, not in the PLCs of the mice infected with less amount $\left(0.4-0.8 \times 10^{8} \mathrm{CFUs}\right)$ of E. coli. (3) The giant cells could constitute $20 \%$ of the PLCs. Possibly, the giant cells were developed from the regular PMNs after engulfing a large amount of bacterial pathogens. Biologically, the appearance of the giant cells could be used as a cell marker for signifying a real danger because the giant cells were intimately correlated with the severity of the infection and the death of the mice.

\section{Conflict of Interests}

The authors declare that there is no conflict of interests.

\section{Acknowledgments}

The authors are grateful to Xiaoping $\mathrm{Hu}$, Yanmei Wang, and Peiyin Zhang for their technical support. This study is supported by National Natural Science Foundation of China (81471888).

\section{References}

[1] N. C. Riedemann, R.-F. Guo, and P. A. Ward, "The enigma of sepsis," The Journal of Clinical Investigation, vol. 112, no. 4, pp. 460-467, 2003.

[2] M. Sartelli, F. M. Abu-Zidan, L. Ansaloni et al., "The role of the open abdomen procedure in managing severe abdominal sepsis: WSES position paper," World Journal of Emergency Surgery, vol. 10, article 35, 2015.

[3] M. Sartelli, F. Catena, L. Ansaloni et al., "Complicated intraabdominal infections worldwide: the definitive data of the CIAOW study," World Journal of Emergency Surgery, vol. 9, article 37, 2014.

[4] F. Sônego, J. C. Alves-Filho, and F. Q. Cunha, "Targeting neutrophils in sepsis," Expert Review of Clinical Immunology, vol. 10, no. 8, pp. 1019-1028, 2014.

[5] B. Amulic, C. Cazalet, G. L. Hayes, K. D. Metzler, and A. Zychlinsky, "Neutrophil function: from mechanisms to disease," Annual Review of Immunology, vol. 30, pp. 459-489, 2012.

[6] Y. Tsuda, H. Takahashi, M. Kobayashi, T. Hanafusa, D. N. Herndon, and F. Suzuki, "Three different neutrophil subsets exhibited in mice with different susceptibilities to infection by methicillin-resistant Staphylococcus aureus," Immunity, vol. 21, no. 2, pp. 215-226, 2004.

[7] C. Pozzi, G. Lofano, F. Mancini et al., "Phagocyte subsets and lymphocyte clonal deletion behind ineffective immune response to Staphylococcus aureus," FEMS Microbiology Reviews, vol. 39, no. 5, pp. 750-763, 2015.

[8] A. Savva and T. Roger, "Targeting toll-like receptors: promising therapeutic strategies for the management of sepsis-associated 
pathology and infectious diseases," Frontiers in Immunology, vol. 4, article 387, 2013.

[9] K. Miyake and M. Onji, "Endocytosis-free DNA sensing by cell surface TLR9 in neutrophils: rapid defense with autoimmune risks," European Journal of Immunology, vol. 43, no. 8, pp. 20062009, 2013.

[10] D. Lindau, J. Mussard, B. J. Wagner et al., "Primary blood neutrophils express a functional cell surface Toll-like receptor 9," European Journal of Immunology, vol. 43, no. 8, pp. 2101-2113, 2013.

[11] G. Plitas, B. M. Burt, H. M. Nguyen, Z. M. Bamboat, and R. P. DeMatteo, "Toll-like receptor 9 inhibition reduces mortality in polymicrobial sepsis," The Journal of Experimental Medicine, vol. 205, no. 6, pp. 1277-1283, 2008.

[12] C. S. Calfee and M. A. Matthay, "Clinical immunology: culprits with evolutionary ties," Nature, vol. 464, no. 7285, pp. 41-42, 2010.

[13] Q. Zhang, M. Raoof, Y. Chen et al., "Circulating mitochondrial DAMPs cause inflammatory responses to injury," Nature, vol. 464, no. 7285, pp. 104-107, 2010.

[14] Y. Iwakura, H. Ishigame, S. Saijo, and S. Nakae, "Functional specialization of interleukin-17 family members," Immunity, vol. 34, no. 2, pp. 149-162, 2011.

[15] N. Isailovic, K. Daigo, A. Mantovani, and C. Selmi, "Interleukin17 and innate immunity in infections and chronic inflammation," Journal of Autoimmunity, vol. 60, pp. 1-11, 2015.

[16] L. Li, L. Huang, A. L. Vergis et al., "IL-17 produced by neutrophils regulates IFN- $\gamma$-mediated neutrophil migration in mouse kidney ischemia-reperfusion injury," The Journal of Clinical Investigation, vol. 120, no. 1, pp. 331-342, 2010.

[17] P. R. Taylor, S. Roy, S. M. Leal Jr. et al., "Activation of neutrophils by autocrine IL-17A-IL-17RC interactions during fungal infection is regulated by IL-6, IL-23, ROR $\gamma \mathrm{t}$ and dectin2," Nature Immunology, vol. 15, no. 2, pp. 143-151, 2014.

[18] K. Garraud, A. Cleret, J. Mathieu et al., "Differential role of the interleukin-17 axis and neutrophils in resolution of inhalational anthrax," Infection and Immunity, vol. 80, no. 1, pp. 131-142, 2012.

[19] J. L. Werner, M. A. Gessner, L. M. Lilly et al., "Neutrophils produce interleukin 17A (IL-17A) in a Dectin-1- and IL-23dependent manner during invasive fungal infection," Infection and Immunity, vol. 79, no. 10, pp. 3966-3977, 2011.

[20] H. Ishida, T. Imai, K. Suzue et al., "IL-23 protection against Plasmodium berghei infection in mice is partially dependent on IL-17 from macrophages," European Journal of Immunology, vol. 43, no. 10, pp. 2696-2706, 2013.

[21] C. Nathan, "Neutrophils and immunity: challenges and opportunities," Nature Reviews Immunology, vol. 6, no. 3, pp. 173-182, 2006.

[22] T. N. Mayadas, X. Cullere, and C. A. Lowell, “The multifaceted functions of neutrophils," Annual Review of Pathology, vol. 9, pp. 181-218, 2014

[23] S. Karbach, A. L. Croxford, M. Oelze et al., "Interleukin 17 drives vascular inflammation, endothelial dysfunction, and arterial hypertension in psoriasis-like skin disease," Arteriosclerosis, Thrombosis, and Vascular Biology, vol. 34, no. 12, pp. 2658-2668, 2014.

[24] H. Li, R. Prasad, S. K. Katiyar, N. Yusuf, C. A. Elmets, and H. Xu, "Interleukin-17 mediated inflammatory responses are required for ultraviolet radiation-induced immune suppression," Photochemistry and Photobiology, vol. 91, no. 1, pp. 235-241, 2015.
[25] G. F. Sonnenberg and D. Artis, "Innate lymphoid cells in the initiation, regulation and resolution of inflammation," Nature Medicine, vol. 21, no. 7, pp. 698-708, 2015.

[26] K. Nishikawa, N. Seo, M. Torii et al., "Interleukin-17 induces an atypical M2-Like macrophage subpopulation that regulates intestinal inflammation," PLoS ONE, vol. 9, no. 9, Article ID e108494, 2014.

[27] M. Hoshi, Y. Osawa, H. Ito et al., "Blockade of indoleamine 2,3-dioxygenase reduces mortality from peritonitis and sepsis in mice by regulating functions of $\mathrm{CD}_{11 \mathrm{~b}^{+}}$peritoneal cells," Infection and Immunity, vol. 82, no. 11, pp. 4487-4495, 2014.

[28] M. A. Flierl, D. Rittirsch, H. Gao et al., "Adverse functions of IL-17A in experimental sepsis," The FASEB Journal, vol. 22, no. 7, pp. 2198-2205, 2008. 


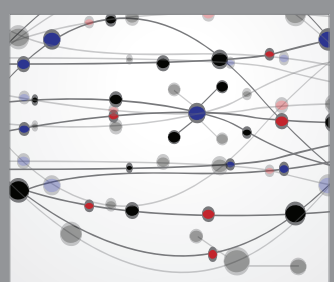

The Scientific World Journal
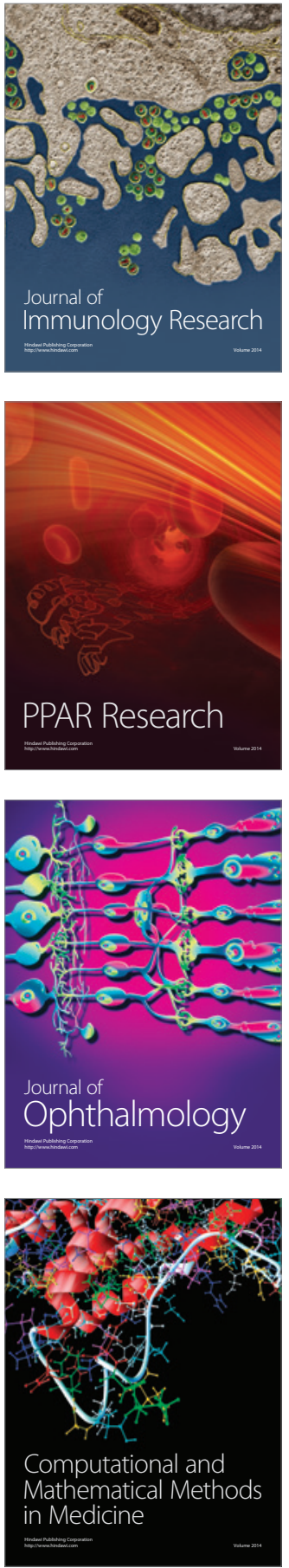

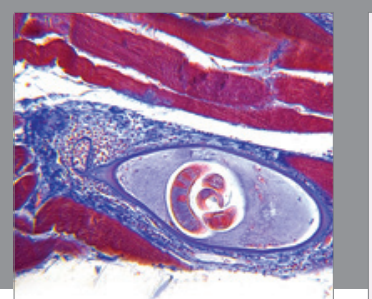

Gastroenterology Research and Practice

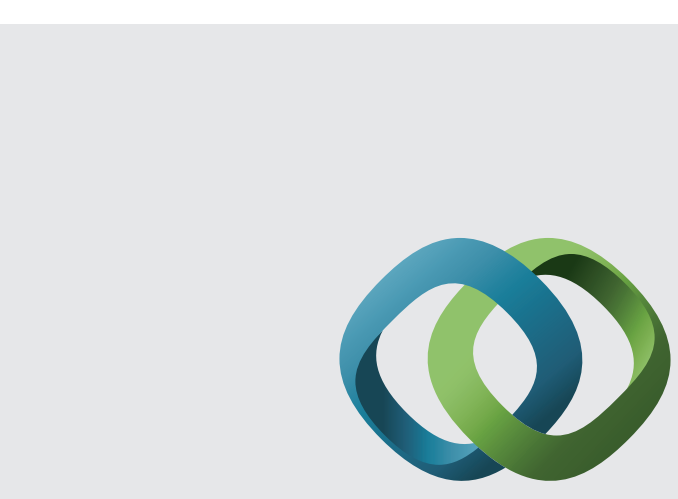

\section{Hindawi}

Submit your manuscripts at

http://www.hindawi.com
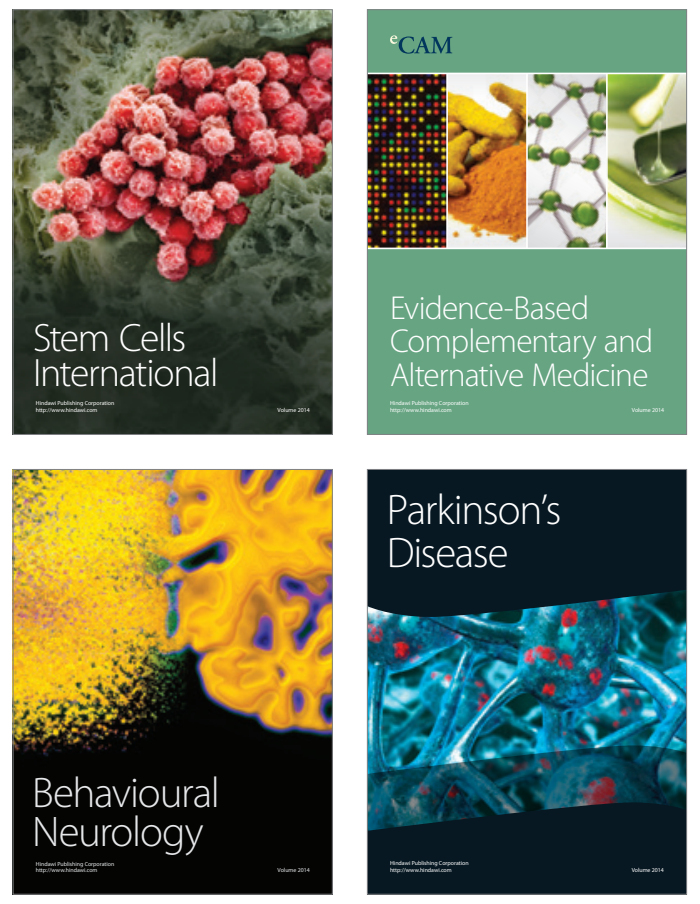
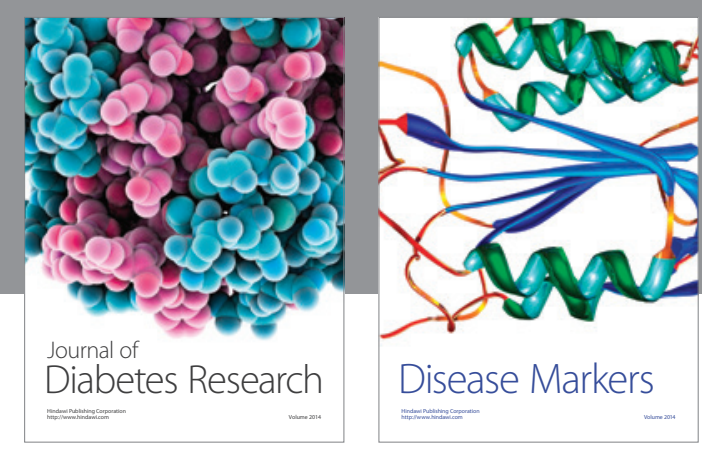

Disease Markers
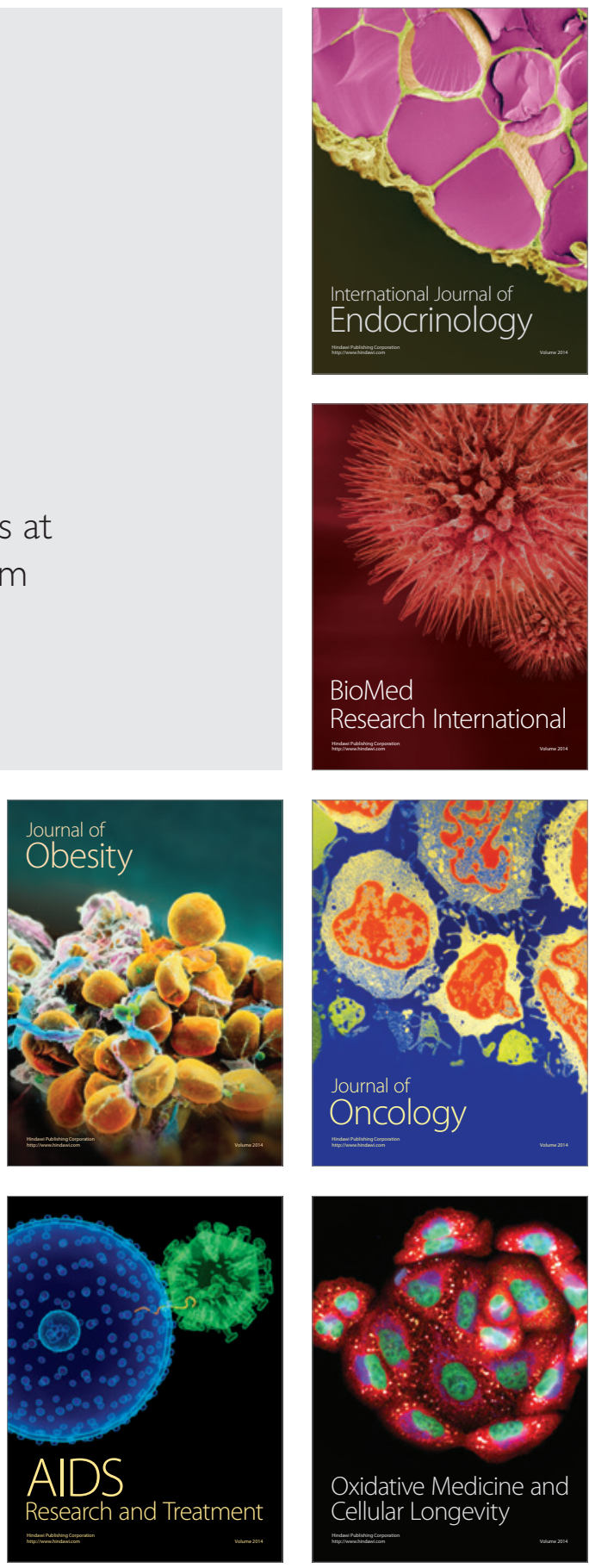